\title{
Inhibition of orf virus replication in goat skin fibroblast cells by the HSPA1B protein, as demonstrated by iTRAQ-based quantitative proteome analysis
}

\author{
Jun-hong Hao ${ }^{1} \cdot$ Han-jin Kong ${ }^{1} \cdot$ Ming-hao Yan ${ }^{1} \cdot$ Chao-chao Shen ${ }^{1} \cdot$ Guo-wei Xu ${ }^{1}$ - Da-jun Zhang ${ }^{1}$. \\ Ke-shan Zhang ${ }^{1}$ (I) $\cdot$ Hai-xue Zheng ${ }^{1} \cdot$ Xiang-tao Liu $^{1}$
}

Received: 8 March 2020 / Accepted: 26 July 2020 / Published online: 2 September 2020

(c) Springer-Verlag GmbH Austria, part of Springer Nature 2020

\begin{abstract}
Orf virus (ORFV) infects sheep and goat tissues, resulting in severe proliferative lesions. To analyze cellular protein expression in ORFV-infected goat skin fibroblast (GSF) cells, we used two-dimensional liquid chromatography-tandem mass spectrometry coupled with isobaric tags for relative and absolute quantification (iTRAQ). The proteomics approach was used along with quantitative reverse transcription polymerase chain reaction (RT-qPCR) to detect differentially expressed proteins in ORFV-infected GSF cells and mock-infected GSF cells. A total of 282 differentially expressed proteins were identified. It was found that 222 host proteins were upregulated and 60 were downregulated following viral infection. We confirmed that these proteins were differentially expressed and found that heat shock 70-kDa protein 1B (HSPA1B) was differentially expressed and localized in the cytoplasm. It was also noted that HSPA1B caused inhibition of viral proliferation, in the middle and late stages of viral infection. The differentially expressed proteins were associated with the biological processes of viral binding, cell structure, signal transduction, cell adhesion, and cell proliferation.
\end{abstract}

\section{Introduction}

Orf, which is caused by orf virus (ORFV), is one of the most widespread viral diseases worldwide. Although ORFV mainly infects sheep and goats, it can also infect other ruminants and other mammals [18]. Genes involved in virulence and pathogenesis are distributed in the ITR regions of the ORFV genome. The virus encodes involved in immunomodulation, including viral-interleukin 10 (vIL-10, ORFV127), vascular endothelial growth factor (VEGF, ORFV132), orf virus interferon resistance protein (OVIFNR, ORFV020), chemokine binding protein (CBP, ORFV112), granulocyte-macrophage colony-stimulating factor/interleukin-2 (GM-CSF/IL-2) inhibitory protein (GIF, ORFV117), nuclear

Handling Editor: William G Dundon.

Ke-shan Zhang

vetzks009@163.com

1 State Key Laboratory of Veterinary Etiological Biology, National Foot-and-Mouth Disease Reference Laboratory, Lanzhou Veterinary Research Institute of Chinese Academy of Agriculture Science, No. 1, Xujiaping, Lanzhou 730046, Gansu, People's Republic of China factor kappa B (NF- $\mathrm{KB}$ ) inhibitory protein (ORFV125), and deoxyuridine 5'-triphosphate pyrophosphatase (dUTPase, ORFV007) [38].

Like other poxviruses, ORFV encodes a range of molecules that play vital roles in immune evasion by the production of anti-inflammatory proteins [13]. These proteins, which are mainly involved in the interaction with host defense mechanisms, include OVIFNR, GIF, vIL-10, and VEGF. A number of these proteins are orthologues of known mammalian proteins, whereas others do not appear to have mammalian counterparts [7, 11-13]. ORFV encodes GIF, which is a novel secreted inhibitor of the cytokines GMCSF and IL-2 [7]. GIF co-localizes with ORFV in infected epidermal cells, as detected by immunohistochemistry (IHC) [13]. Both ORFV and ovine IL-10 (vIL-10 and ovIL$10)$ inhibit production of tumor necrosis factor- $\alpha$ (TNF- $\alpha$ ) and IL-8 from macrophages and keratinocytes as well as production of interferon gamma (IFN- $\gamma$ ) from activated lymphocytes [10]. The viral VEGF is important for virulence $[25,34,40]$. It is mitogenic to endothelial cells and promotes angiogenesis in the underlying dermis as well as proliferation of epidermal cells and activation of VEGF receptors. Aside from an array of immunomodulatory factors produced by ORFV, poxviruses also produced a class 
of proteins, namely ankyrin (ANK) repeat proteins [28], which can also promote viral survival. A proteomic analysis of host cellular responses to viral infection may provide new insights into the cellular mechanisms involved in viral pathogenesis.

The isobaric tag for relative and absolute quantitation (iTRAQ) technique allows comprehensive, comparative, and quantitative determination of protein expression [33]. This technique has been extensively applied to proteome analysis [3, 14, 15, 33, 39]. iTRAQ simultaneously identifies and quantifies peptides by measuring peak intensities of reporter ions using tandem mass spectroscopy (MS/MS) and has been developed to identify biomarkers for various viral diseases $[2,41]$. This method has been widely utilized to study the mechanisms of viral infection through the comparative analysis of cellular protein profiles. In the present study, a comparative iTRAQ-based proteomic analysis was conducted to analyze the changes in cellular proteins of goat skin fibroblast (GSF) cells exposed to ORFV in vitro at specific time points. The experiments were performed to investigate functional changes occurring in GSF cells infected by ORFV. This is the first study on the interactions of ORFV with its host using a proteomics approach. The purpose of the present study was to investigate the adaptability and proliferation of ORFV in goat skin fibroblasts. Hence, the iTRAQ-2D-LC-MS/MS technology was used to analyze proteomic changes in ORFV-infected GSF cells. Quantitative reverse transcription polymerase chain reaction (RTqPCR) and other methods were applied to identify differentially expressed proteins and to further analyze and confirm the function of the differentially expressed proteins and heat shock 70-kDa protein 1B (HSPA1B) in ORFV-infected host cells. These data provide a foundation for mapping of gene regulatory networks that are affected by ORFV infection.

\section{Materials and methods}

\section{Cell culture and virus infection}

GSF cells were purchased from the Kunming Institute of Zoology, Chinese Academy of Sciences (Kunming, China) and cultured in complete Dulbecco's modified Eagle's medium (DMEM; HyClone Laboratories Inc., Logan, UT, USA), containing $10 \%$ fetal bovine serum (FBS; Gibco, New York, NY, USA) in an incubator with $5 \% \mathrm{CO}_{2}$. The GSF cell line was tested for mycoplasma contamination, which showed an appropriate microscopic morphology. ORFV was isolated and stored in our laboratory for further experiments. ORFV was passaged continuously for 15 generations on GSFs, virus samples were selected after the 1st, 5th, 10th, and 15th generations, and the viral genome was extracted for B2L gene detection. A 1137-bp fragment of the genome corresponding to the ORFV B2L gene was sequenced, and found to be identical to an ORFV B2L gene sequence published in the Gene Bank database (GU320351).

\section{Growth curve of ORFV in GSF cells}

To analyze the growth of ORFV in GSF cells, the cells were infected at an MOI of 0.1 in a 24-well plate, and uninfected cells served as a control. Samples were collected at 2, 12, 18, $24,36,48$, and $60 \mathrm{~h}$ postinfection. The ORFV copy number was estimated using RT-qPCR.

\section{Sample preparation}

The cultured GSF cells were divided into an experimental group and a control group. When the cells reached about $80 \%$ confluency, $500 \mu \mathrm{L}$ of ORFV suspension (MOI, 0.1) was added to the cells in the experimental group, and DMEM was added to the cells in the control group. The cells were incubated for $1 \mathrm{~h}$ and washed three times with phosphate-buffered saline (PBS), and DMEM medium containing $2 \%$ FBS was added. The cells were collected and protein samples were prepared after $35 \mathrm{~h}$. The culture medium was discarded, and the cells were washed three times with cold PBS, scraped with a cell scraper, and collected in a centrifuge tube. The cells were pelleted by centrifugation at $2000 \mathrm{rpm}$ for $3 \mathrm{~min}$, resuspended and washed two times, and the final cell pellet was stored at $-80{ }^{\circ} \mathrm{C}$ for further experiments.

\section{Protein extraction}

Five hundred $\mu \mathrm{L}$ of protein lysate was added to the sample and lysed on ice. Phenylmethylsulfonyl fluoride (PMSF) and dithiothreitol (DTT) with final concentrations of 1 and $10 \mathrm{mM}$, respectively, were added. After sonication in an ice bath for $15 \mathrm{~min}$, the sample was centrifuged, and the supernatant was treated at $56^{\circ} \mathrm{C}$ for $1 \mathrm{~h}$ to reduce disulfide bonds. Next, iodoacetamide (IAM) was added to a final concentration of $55 \mathrm{mM}$, and the sample was kept in the dark for 45 min to block cysteine alkylation. An appropriate amount of cold acetone was added, and the sample was stored at $-20{ }^{\circ} \mathrm{C}$ for $2 \mathrm{~h}$. The sample centrifuged at $14,000 \mathrm{rpm}$ for $20 \mathrm{~min}$, the supernatant was discarded, and $200 \mu \mathrm{l}$ of $0.5 \mathrm{mM}$ tetraethylammonium borohydride (TEAB) was added to the pellet, which was sonicated for $15 \mathrm{~min}$, and centrifuged at $14,000 \mathrm{rpm}$ for $20 \mathrm{~min}$.

\section{Protein concentration measurement}

Protein quantification was done by the Bradford method, using prepare a standard curve made from series of dilutions 
of bovine serum albumin (BSA) and measuring absorbance at $595 \mathrm{~nm}$.

\section{Protein digestion and iTRAQ labeling}

One hundred $\mu$ g of protein was trypsinized for $12 \mathrm{~h}$. After enzymatic digestion, the peptide was dried using a vacuum centrifugal pump and reconstituted with $0.5 \mathrm{M}$ TEAB. iTRAQ labeling was done according to the manufacturer's instructions. Labeling reagent 116 was used to label the experimental group, and labeling reagent 119 was used to label the control group. After incubation at room temperature for $2 \mathrm{~h}$, the labeled peptides of each group were mixed and separated by liquid-phase chromatography using a strong cation-exchange (SCX) column.

\section{SCX chromatography}

An LC-20AB high-performance liquid chromatography (HPLC) pump system (Shimadzu, Tokyo, Japan) and a $4.6 \times 250-\mathrm{mm}$ separation column were used for liquid-phase separation of the samples. The mixed peptides were labeled were reconstituted and $4 \mathrm{ml}$ of buffer A. Gradient elution was performed at a rate of $1 \mathrm{ml} / \mathrm{min}$. The first elution was performed with buffer A for $10 \mathrm{~min}$, which was gradually mixed with 5-35\% buffer B for $11 \mathrm{~min}$, and finally mixed with $35-80 \%$ buffer B and eluted for $1 \mathrm{~min}$. The entire elution process was monitored by measuring the absorbance at $214 \mathrm{~nm}$, and 20 components were eventually selected. Each component was desalted separately using a Strata-X C18 column (Phenomenex, Torrance, CA, USA) and then freeze-dried.

\section{Capillary HPLC}

The concentration of each component that was adjusted to about $0.5 \mu \mathrm{g} / \mu \mathrm{l}$ with buffer $\mathrm{C}$ and centrifuged at $20,000 \mathrm{rpm}$ for $10 \mathrm{~min}$ to remove insoluble matter. Eight microliters of each component (about $4 \mu \mathrm{g}$ of protein) was separated using a Shimadzu LC-20AD HPLC system (Shimadzu, Tokyo, Japan). The column included a trap column and an analytical column. The separation parameters were as follows: injection for $4 \mathrm{~min}$ at a flow rate of $8 \mathrm{~nL} / \mathrm{min}$, washing at a flow rate of $300 \mathrm{~nL} / \mathrm{min}$ for $40 \mathrm{~min}$, washing with gradient buffer D from $2-35 \%$ and then from $35-80 \%$, and washing with $80 \%$ buffer D for 4 min and buffer $\mathrm{C}$ for $1 \mathrm{~min}$.

\section{Electrospray ionization mass spectrometry (ESI-MS)}

The peptides were separated using a Q-Exactive mass spectrometer. The primary MS resolution was set to 70,000 full width at half maximum (FWHM). The peptides were screened using a high-energy collision mode with a collision energy of $27( \pm 12)$. Secondary fragments were detected in Orbi with a resolution of 17,500 FWHM. In addition, 15 secondary spectra were plotted for primary precursor ions with peak intensities in excess of 20,000, and primary and secondary scanning was performed. Scanned mass-to-charge ratios ranged from 350 to $2000 \mathrm{Da}$.

\section{MS data analysis}

The original mass spectrum file was converted to MGF format. The quantitative data were analyzed by iTRAQ Result Multiple File Distiller, and the MGF file was used as an original file with Mascot2.3.02 protein identification software. A selected sheep genome annotation database (22134 sequences) and ORFV virus from the NCBI database (150 sequences) were used for searching and combined with the quantitative results.

\section{Bioinformatics analysis}

Functional annotation, subcellular localization, and metabolic pathway analysis of the identified differentially expressed proteins were carried out. The hypergeometric test was used to find Gene Ontology (GO) entries that were enriched compared with other proteins. These differentially expressed proteins were compared with the Clusters of Orthologous Groups of proteins (COG) database to predict the possible functions of these proteins and perform statistical analysis on their functional classification.

\section{RT-qPCR}

Specific primers (Table 1) were designed to amplify various target genes simultaneously according to the corresponding gene sequences of MS/MS-identified proteins, and the available genetic information was deposited in the GenBank database. The analysis was conducted using Lasergene sequence analysis software (DNASTAR, Inc., Madison, WI, USA). GSF monolayers were inoculated with ORFV for $35 \mathrm{~h}$ and washed three times with ice-cold PBS. They were then harvested by centrifugation at $1,000 \mathrm{rpm}$ for $10 \mathrm{~min}$. Total cellular RNA was extracted using an RNeasy Mini Kit (QIAGEN GmbH, Hilden, Germany) according to the manufacturer's protocol. The RNA concentration was measured using a spectrophotometer $(260 / 280 \mathrm{~nm})$. RT-qPCR was performed using an Mx3005P Real-Time PCR System (Agilent Technologies, Inc., Santa Clara, CA, USA). A reverse transcription step was first performed at $42{ }^{\circ} \mathrm{C}$ for 5 min to make cDNA from total RNA. The PCR procedure consisted of a denaturation step at $95{ }^{\circ} \mathrm{C}$ for $10 \mathrm{~s}$, followed by 40 cycles of amplification, each consisting of an extra denaturation step at $95{ }^{\circ} \mathrm{C}$ for $5 \mathrm{~s}$ and a primer annealing step at $60{ }^{\circ} \mathrm{C}$ for $34 \mathrm{~s}$. Melting curves were plotted, and 
Table 1 Primers used for the goat target genes based on the corresponding gene sequences of the identified proteins. Specific primers were designed to simultaneously amplify various target genes according to the corresponding gene sequences of identified proteins, and the available gene information was deposited in the GenBank database

\begin{tabular}{|c|c|}
\hline Gene name & Primer sequence $\left(5^{\prime}-3^{\prime}\right)$ \\
\hline \multirow[t]{2}{*}{ BCLF1 } & F: AAGATACATTTGAACACGACCCG \\
\hline & R: ATCCATTTCCAACAGAACCAGAC \\
\hline \multirow[t]{2}{*}{ PARP1 } & F: TCGGGCTCGTGGACATCGT \\
\hline & R: GGCATCTGCTCCAGTTTGT \\
\hline \multirow[t]{2}{*}{ COR1B } & F: TTGCCCTTCTACGACCCTGAT \\
\hline & R: GGCTCCTTGCTGGTGAATGTA \\
\hline \multirow[t]{2}{*}{ MAP4 } & F: GGCTCCCAATGCTTCTGC \\
\hline & R: CCCGTAGGCGGTTTCTGT \\
\hline \multirow[t]{2}{*}{ 6PGD } & F: ATGGCTTTGTGGTCTGTGC \\
\hline & R: CCGTCTCATGGTATCCCTGTAT \\
\hline \multirow[t]{2}{*}{ G3P } & F: AAGTTCCACGGCACAGTCA \\
\hline & R: TGGTTCACGCCCATCACAA \\
\hline \multirow[t]{2}{*}{ SC24D } & F: GCTATTATGCGGGTTCG \\
\hline & R: ATCAAGGCTCCAGTGTC \\
\hline \multirow[t]{2}{*}{ ZN207 } & F: TACCTGGGAGAACAGACAT \\
\hline & R: GCTGCGGTTGAAATGAAGT \\
\hline \multirow[t]{2}{*}{ FIS1 } & F: ACAGAGCCGCAGAACAACCA \\
\hline & R: TCCGATGAGTCCAGCCAGTC \\
\hline \multirow[t]{2}{*}{ CDV3 } & F: CCTCCTGCTCCAGTAGTTGTT \\
\hline & R: TTGTGGTGCTTTCCTTGTTGT \\
\hline \multirow[t]{2}{*}{ VMA5A } & F: CCAACTGCTCCTTGAGTCCTA \\
\hline & R: AGCTTCTCCCATCTCCACGA \\
\hline \multirow[t]{2}{*}{ PSME2 } & F: CCCACCCAAGGATGATGAGAT \\
\hline & R: GAAAGCCGCACTTAGGGACTG \\
\hline \multirow[t]{2}{*}{ ACTB } & F: ACACGGTGCCCATCTACGA \\
\hline & R: TTGATGTCACGGACGATTTC \\
\hline \multirow[t]{2}{*}{ GAPDH } & F: AAGTTCCACGGCACAGTCA \\
\hline & R: TGGTTCACGCCCATCACAA \\
\hline \multirow[t]{2}{*}{$\mathrm{B} 2 \mathrm{~L}$} & F: GGGGCGGCGTATTCTTCT \\
\hline & R: GCTGTTCTTGGCGTTCTCG \\
\hline \multirow[t]{2}{*}{ HSPA1B } & F: GGGAGGACTTCGACAACAGG \\
\hline & R: GACAAGGTTCTCTTGGCCCG \\
\hline
\end{tabular}

quantitative analysis of the data was conducted using the 7500 Fast System SDS 1.3.1 software (Applied Biosystems, Foster City, CA, USA). Mock-infected GSF cells were used as a control. The RT-PCR products were analyzed by electrophoresis in a $2 \%$ agarose gel.

\section{Subcellular localization of HSPA1B}

Cells were seeded into 6-well plates and cultured overnight in DMEM in the presence of $10 \%$ FBS. The transfection mixture, which contained $2.0 \mu \mathrm{g}$ of plasmid DNA and 6 $\mu \mathrm{L}$ of transfection reagent (Invitrogen, Carlsbad, CA, USA) in $100 \mu \mathrm{L}$ of serum-free DMEM, was mixed for $20 \mathrm{~min}$ at room temperature and subsequently added to each well with complete medium for $24 \mathrm{~h}$. The cells were evaluated for protein expression by fluorescence microscopy at $24-48 \mathrm{~h}$ posttransfection and then were fixed by conventional methods and stained with 4',6-diamidino-2-phenylindole (DAPI). The cellular distribution of HSPA1B was analyzed by confocal laser scanning microscopy (CLSM).

\section{Measurement of the effect of HSPA1B on ORFV replication}

In order to examine the influence of HSPA1B on the proliferation of ORFV, GSF cells were transiently transfected with pEFGP-HSPA1B plasmids as described previously. Subsequently, the cells were infected with ORFV at an MOI of 0.1. After incubation for $1 \mathrm{~h}$, the cells were washed three times with PBS and DMEM containing $2 \%$ FBS was added. The cultured cells were collected at 15,24 , and $36 \mathrm{~h}$ postinfection and the viral DNA was quantitated using RT-qPCR.

\section{RNA interference}

Small interfering RNA (siRNA) was chemically synthesized by Gene Pharma (Shanghai, China). The knockdown of endogenous HSPA1B was carried out by transfection of GSF cells with HSPA1B siRNA (517) (5'- UUUGUAGCU CACCUGCACCTT-3'), HSPA1B siRNA (1258) (5'- GUU GAAGAAGUCCUGCAGCTT-3'), and HSPA1B siRNA (1486) (5'- GUAGGUGGUGAAGAUCUGCTT-3') using Lipofectamine 2000. Nontargeting siRNA (NC siRNA) was used as a negative control.

\section{Western blot}

For Western blotting, target proteins were resolved by SDS-PAGE and transferred to an Immobilon-P membrane (Millipore). The membrane was blocked and incubated with appropriate primary antibodies and secondary antibodies. Antibody-antigen complexes were visualized using enhanced chemiluminescence detection reagents (Thermo) [42]. Mouse anti-HSPA1B anti- $\beta$-actin antibodies were purchased from Abbkine. Mouse anti-B2L antibody was obtained from the Lanzhou Veterinary Research Institute.

\section{Results}

\section{Growth of ORFV in GSF cells}

In order to assess the growth of ORFV in GSF cells, a one-step growth curve was carried out using RT-qPCR. ORFV was adapted to GSF infection by passaging for 15 
generations. At different time points, the supernatants and the cells were collected, and the copy number of viral DNA was determined by RT-qPCR to prepare a one-step growth curve. The results indicated that the intracellular viral DNA content increased from 2 to $36 \mathrm{~h}$ postinfection and reached the highest level at $36 \mathrm{~h}$. The extracellular viral DNA content gradually increased (Fig. 1A), while the intracellular viral DNA content decreased during this time period, and the extracellular viral DNA content increased to form an $\mathrm{S}$-shaped curve. The eclipse phase was from 0 to $12 \mathrm{~h}$ postinfection, during which the viral content remained at a low level. The logarithmic phase was from 12 to $48 \mathrm{~h}$, and the viral DNA content increased, reaching a peak at $48 \mathrm{~h}$, slowing from 48 to $60 \mathrm{~h}$ postinfection, and gradually reaching a plateau (Fig. 1B).

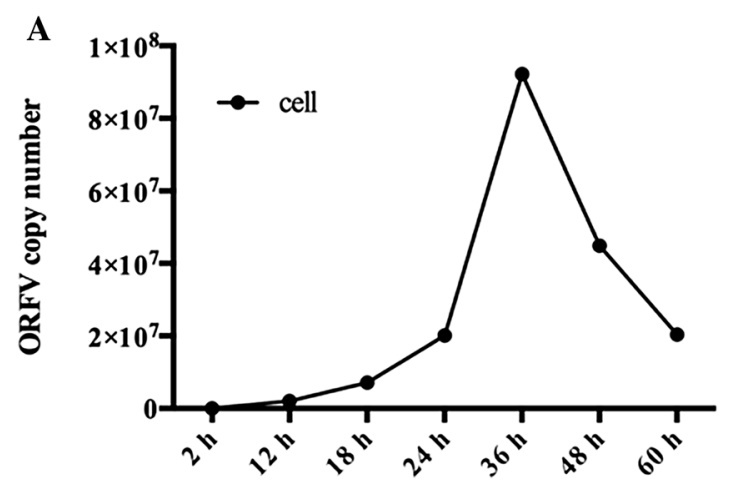

Fig. 1 One-step growth curve of ORFV infection in GSF cells. GSF cells were infected with ORFV at an MOI of 0.1 and cell supernatants and infected cells were collected at 2, 12, 18, 24, 36, 48, and $60 \mathrm{~h}$

\section{Kinetics of ORFV-induced cytopathology in cultured GSF cells}

One of the key parameters for determining virus-induced alterations is the length of time until a cytopathic effect (CPE) is observed in the model system. GSF cells were infected with ORFV at an MOI of approximately 0.1 , and monitored for cell viability and CPE. As shown in Fig. 2, the cells infected with ORFV that were cultured for less than $24 \mathrm{~h}$ demonstrated no detectable CPE (Fig. 2A-B). At $24 \mathrm{~h}$ postinfection, a small number of cells began to swell and had a round shape (Fig. 2C-D). At $60 \mathrm{~h}$, the cells detached from the plate (Fig. 2E) and were completely destroyed after $72 \mathrm{~h}$ postinfection (Fig. 2F-G).

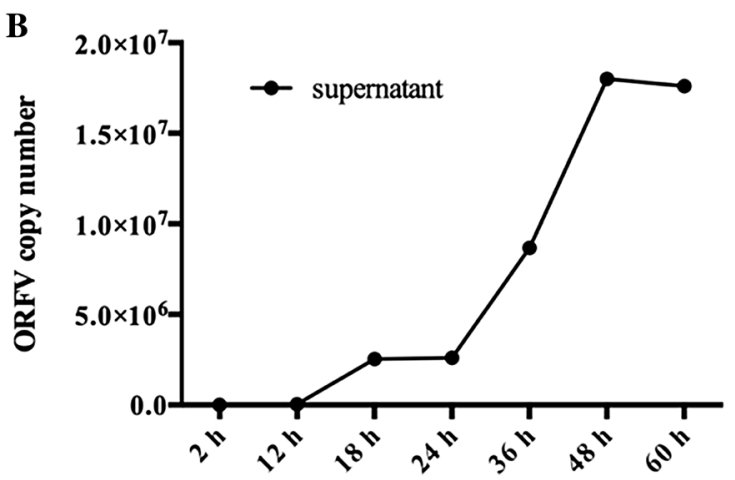

postinfection. RT-qPCR was used to make a one-step growth curve to measure the copy number of the intracellular virus (Fig. 1A) and extracellular virus (Fig. 1B)

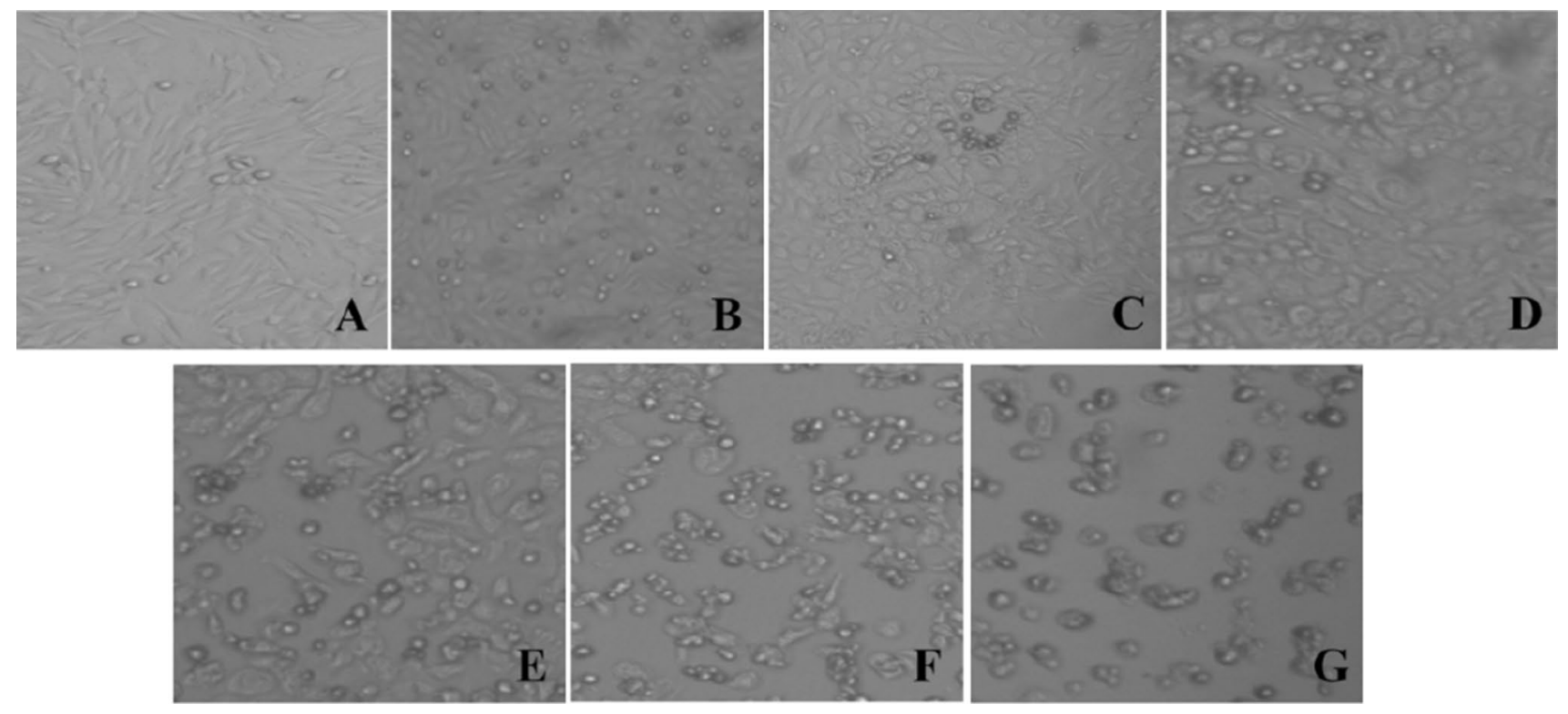

Fig. 2 Kinetics of the ORFV-induced cytopathic effect (CPE) in GSF cells. Cells at about $80 \%$ confluency were infected with ORFV at an MOI of 0.1 or mock infected, and DMEM was added to the cells in the control group, and after $1 \mathrm{~h}$, the cells were washed three times with PBS, and DMEM 2\% FBS was added. Morphological changes were then examined at different time points 


\section{Differentially expressed proteins analyzed by iTRAQ-coupled 2D LC/MS-MS}

The cellular proteins in ORFV-infected and mock-infected GSF cells were extracted for iTRAQ analysis. In total, 10,630 peptides and 2,776 proteins were detected. Of these, 282 proteins were found to be differentially expressed in ORFV-infected GSF cells compared with the mock-infected GSF cells, including 222 significantly upregulated proteins and 60 significantly downregulated proteins. The upregulated proteins are listed in Table 2, and the downregulated proteins are listed in Table 3. Three proteins that are involved in cell killing showed altered expression levels. The levels of CXCL6, IFNG (interferon gamma [IFN $\gamma$ ]), and ALBU increased after infection. In addition, 28 proteins involved in cell proliferation exhibited differential expression. NFIP1, IFNG, TKT, CD9, BAK, HS71B, CSK2B, NPM, HDGF, PA2G4, CDV3, RL23A, THIO, MCM7, CXCL6, YBOX1, RS4X, CYR61, HMOX1, APOD, TANA, RS6, and PAI1 were upregulated, while CAV1, GBG2, ZPR1, MK01, and LAMB2 were downregulated. CXCL6 and IFNG are associated with pathways involved in apoptosis [5, 22] and proliferation [23, 29]. Changes in the levels of biological adhesion proteins were also detected, including PAI1, APOD, CTGF, ADAM9, EZRI, CYR61, CD9, and TKT, which were upregulated, and TBCD, VINC, CO3A1, 2AAA, LAMB2, and PARVA were downregulated. The abundance of the $70-\mathrm{kDa}$ heat shock proteins (HSPs) HSPA6 and HSPA1B increased after infection. Moreover, several ribosomal proteins, including RPS6, RPS17, RPS3, RPS21, RPS18, RPS3A, Rps16, Rps8, RPS4X, Rps23, RPS2, RPS19, RPS12, Rps13, and RPS20 were upregulated (Table 2). However, no ribosomal proteins were downregulated after infection (Table 3 ).

\section{Functional classification of differentially expressed proteins}

To understand the implications of the cellular responses to ORFV infection, these proteins were categorized into three main types using the UniProt Knowledgebase (Swiss-Prot/ TrEMBL) and the GO databases: cellular components, metabolic functions, and biological processes. Cell component ontology refers to subcellular structures, locations, and macromolecular complexes, such as nucleoli, telomeres, and complexes that recognize initiation. Cellular-component-based enrichment analysis identified differentially expressed proteins that are well distributed in cell components (Fig. 3A) and are mainly involved in morphogenesis, protein synthesis, metabolism, the stress response, the ubiquitin-proteasome pathway, cellular processes, metabolic processes, biological regulation, and response to stimuli. Molecular function ontology refers to the function of an individual gene product, such as carbohydrate binding or
ATP hydrolase activity. Molecular-function-based enrichment analysis demonstrated that binding, catalytic activity, structural molecule activity, and enzymatic regulation were influenced by viral infection (Fig. 3B). Biological processes ontology refers to the ordered combination of molecular functions to achieve a wider range of biological functions, such as mitosis or purine metabolism. Enrichment analysis using biological processes indicated that viral infection mainly affected cellular and metabolic processes (Fig. 3C). A protein may have multiple GO annotations. To determine which biological functions were associated with differentially expressed proteins, a significant enrichment analysis of GO functions was carried out on these differentially expressed proteins. The results revealed that these differentially expressed proteins were mainly localized in the cytoplasm, ribosomes and the nucleus (Fig. 3D). Molecular enrichment analysis showed that these differentially expressed proteins included proteins with nucleic acid binding activity, threonine peptidase activity, and growth factor binding activity (Fig. 3E). Gene set enrichment analysis revealed that these differentially expressed proteins were mainly involved in the initiation and termination of transcription, which are related to virus replication and signal transduction processes (Fig. 3F). The identified differentially expressed proteins were compared with the COG database, and possible functions of these proteins were predicted. COG annotation classification indicated that the differentially expressed proteins were mainly involved in functions such as post-translational modification, protein folding, molecular chaperones, translation, ribosome structure and biosynthesis, energy generation and conversion, and signal transduction (Fig. 3G).

\section{Confirmation of proteomic data by RT-qPCR}

Changes in transcription of 12 genes selected from the differentially expressed proteins were analyzed by quantifying their mRNA transcripts. The " $\beta$-actin" (ACTB) gene was used as a control. The pattern of differences in mRNA abundance for these genes between infected and control GSF cells was similar to the pattern observed for the corresponding proteins based on LC-MS/MS data. As shown in Fig. 4, the abundance of BCLF1, MAP4, 6PGD, G3P, ZN207, and CDV3 mRNA increased. The SC24D, FIS1, COR1B, and PSME2 genes were downregulated, whereas the PARP1 gene was upregulated. An inconsistency between the RT-qPCR data and the LC-MS/MS data was observed for VMA5A, which was downregulated in the RT-qPCR analysis and upregulated in the LC-MS/MS analysis. This inconsistency might have been due to post-translational modifications, such as methylation, phosphorylation, or acetylation, or to differences in protein degradation rates for unknown reasons. These data provide transcriptional 


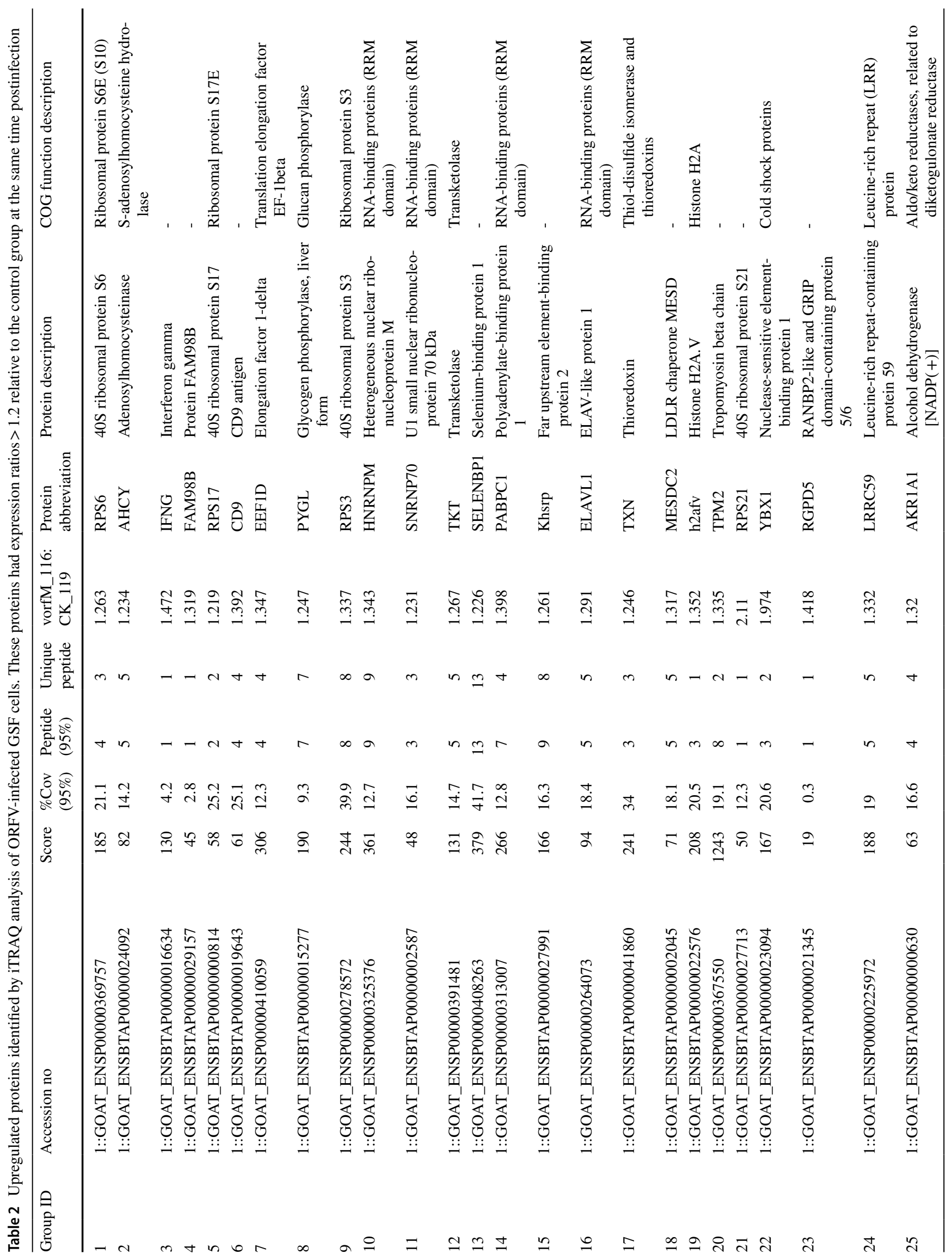




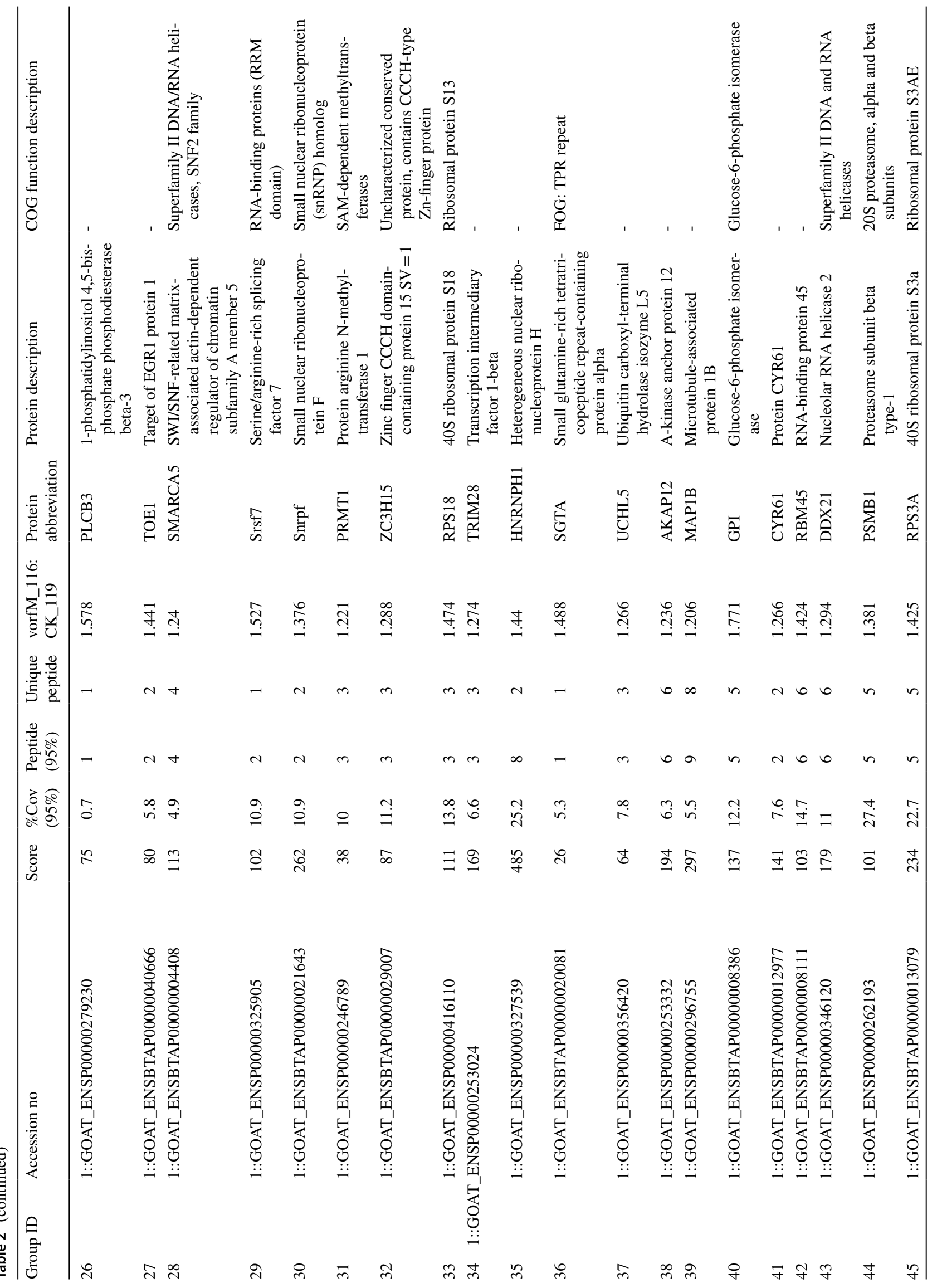




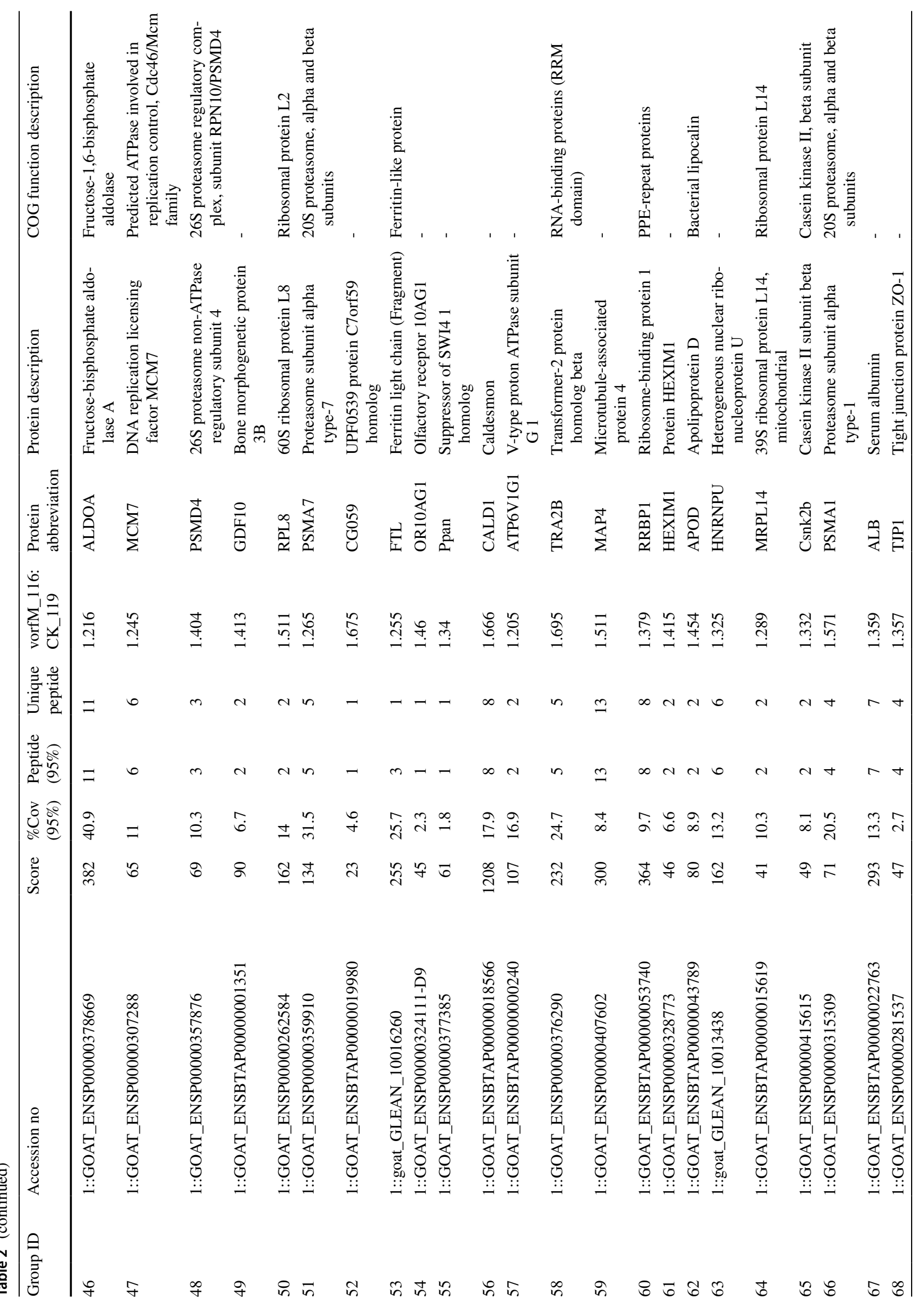




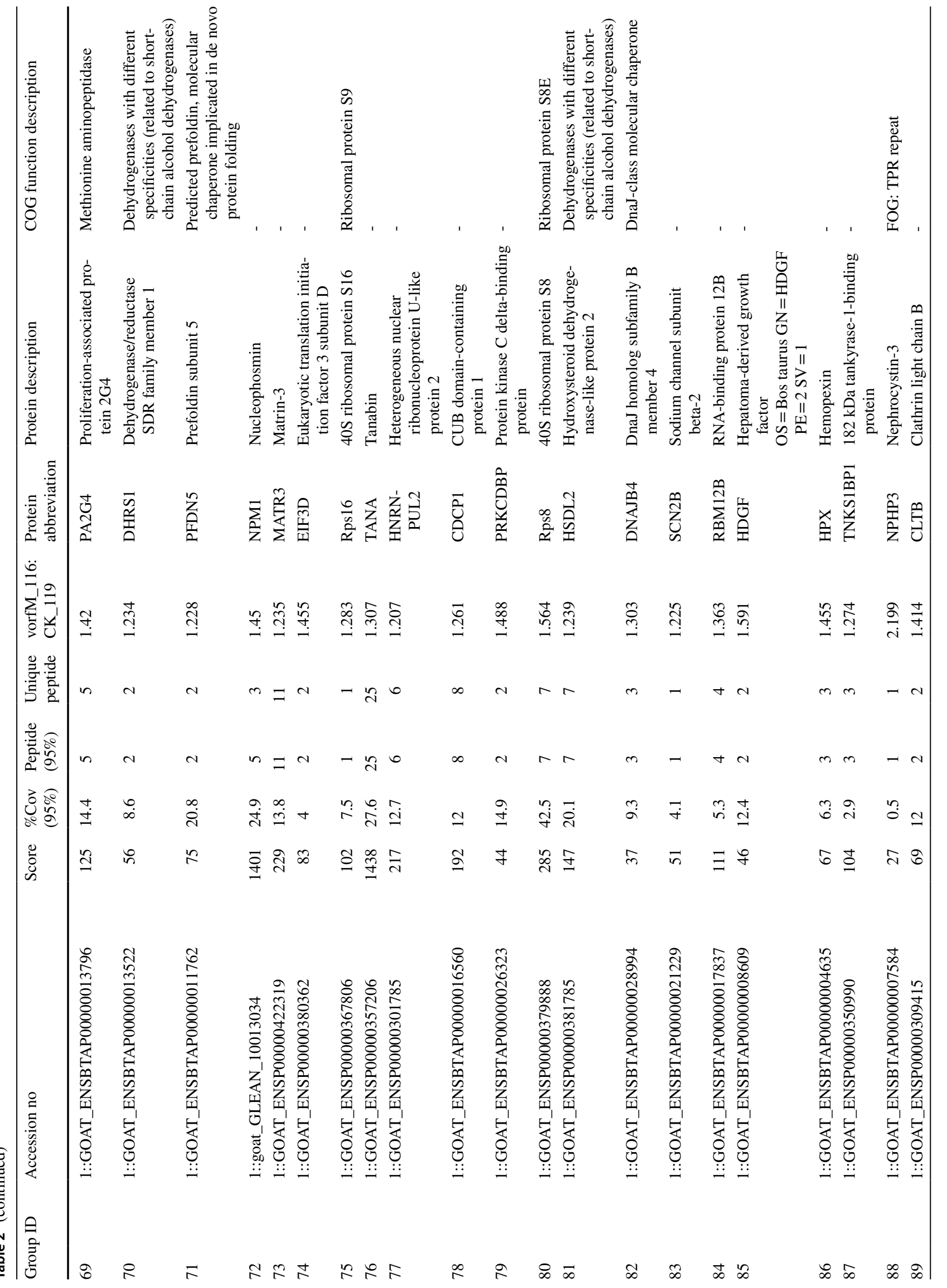




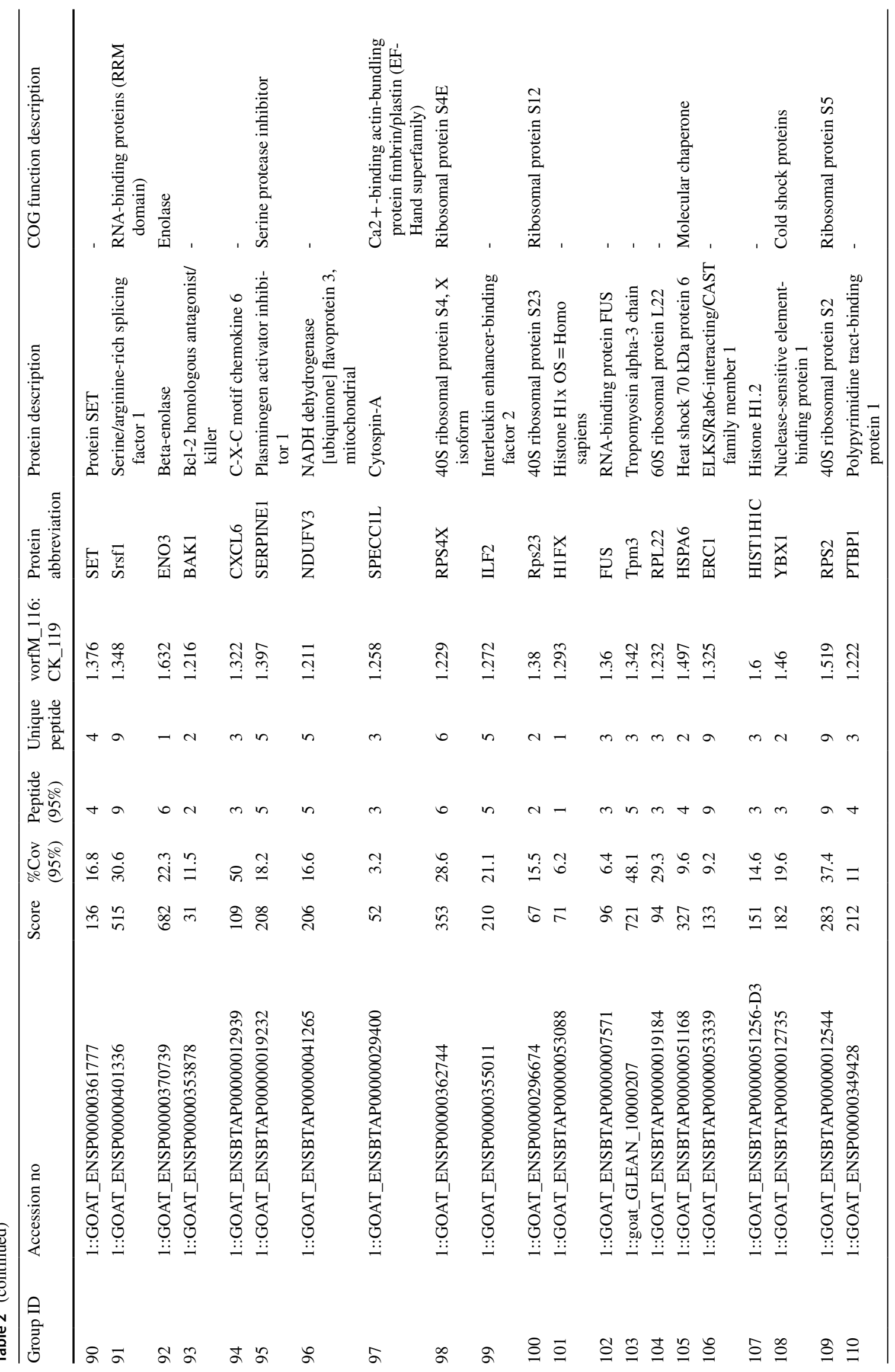




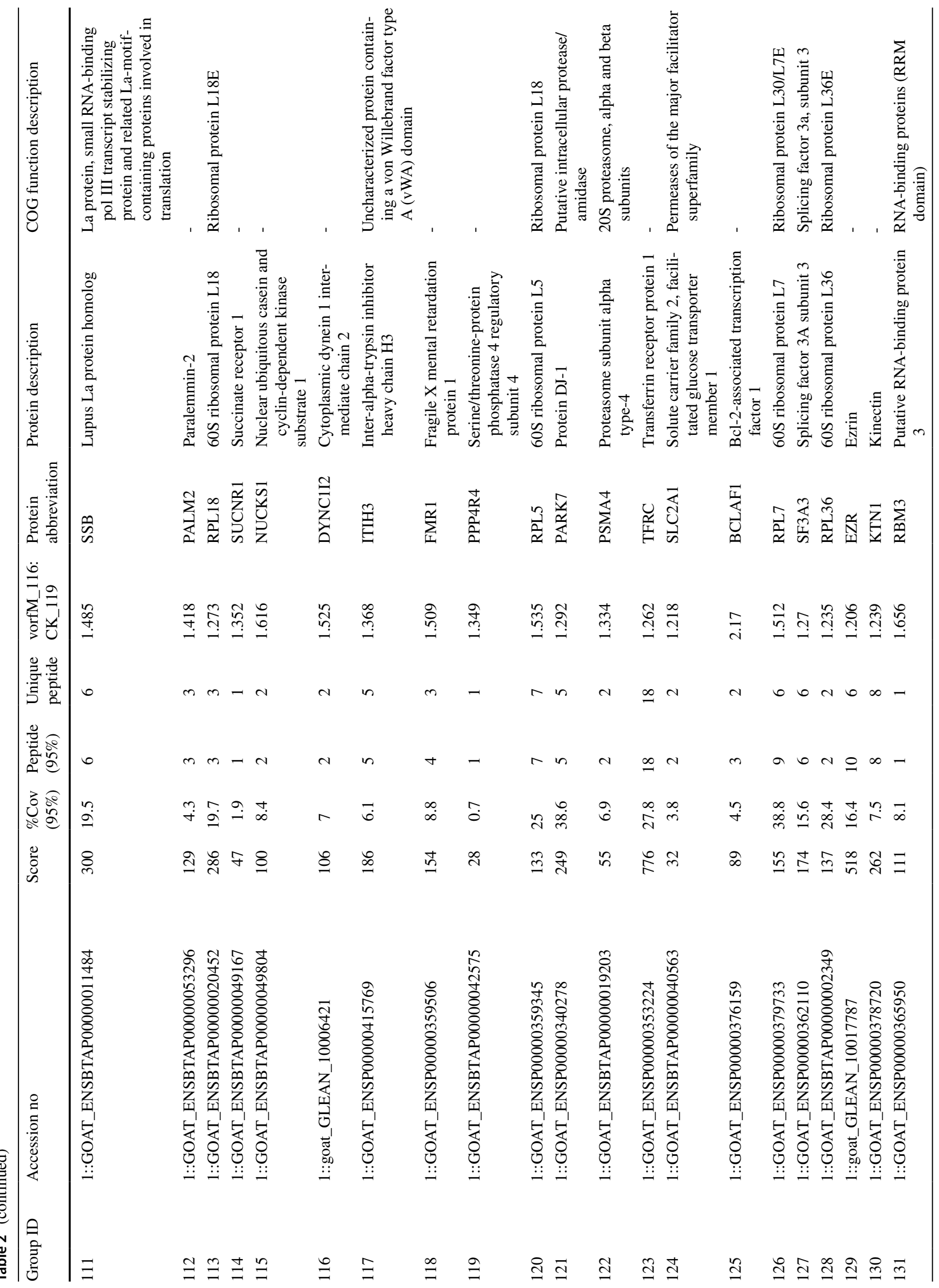




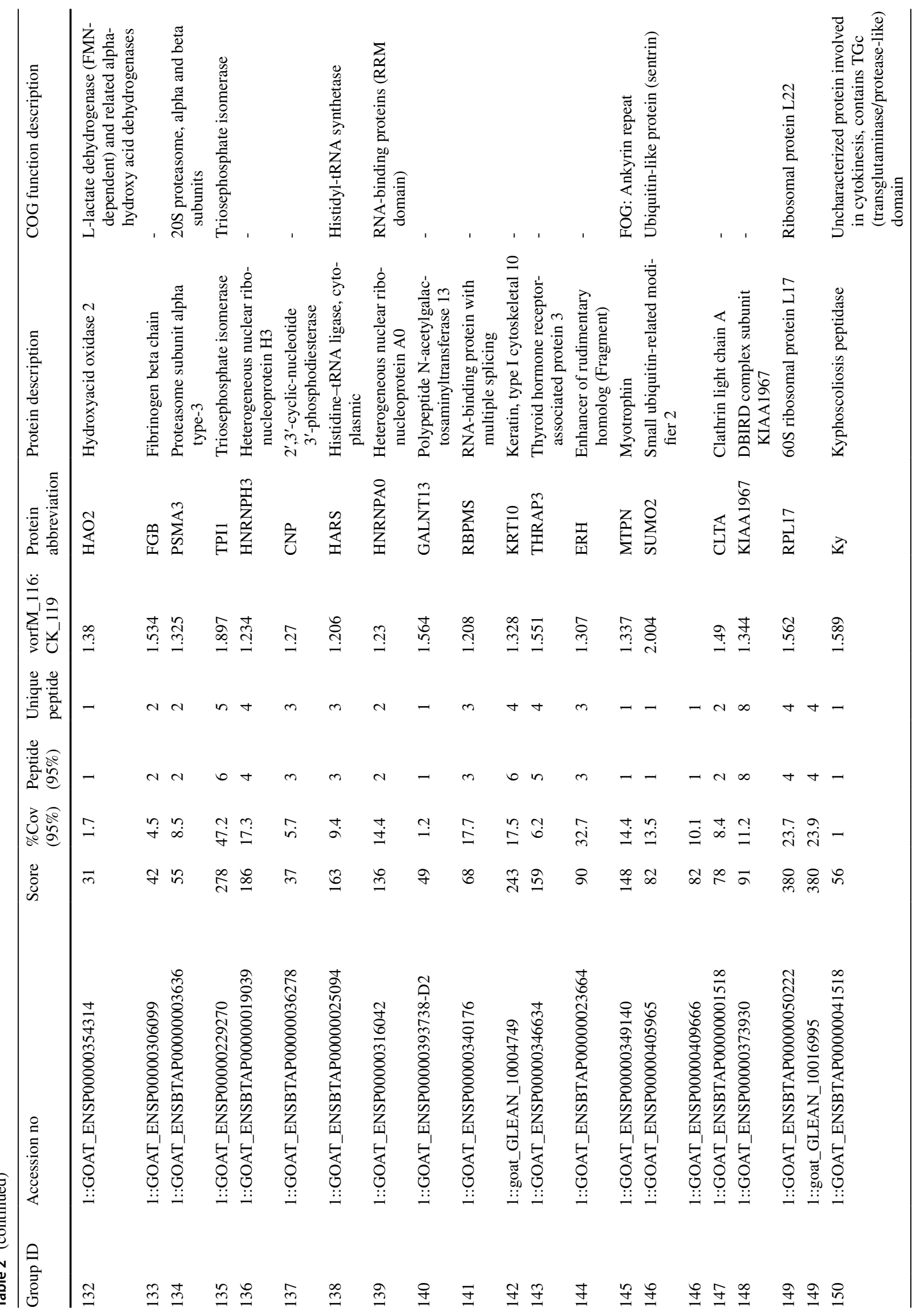




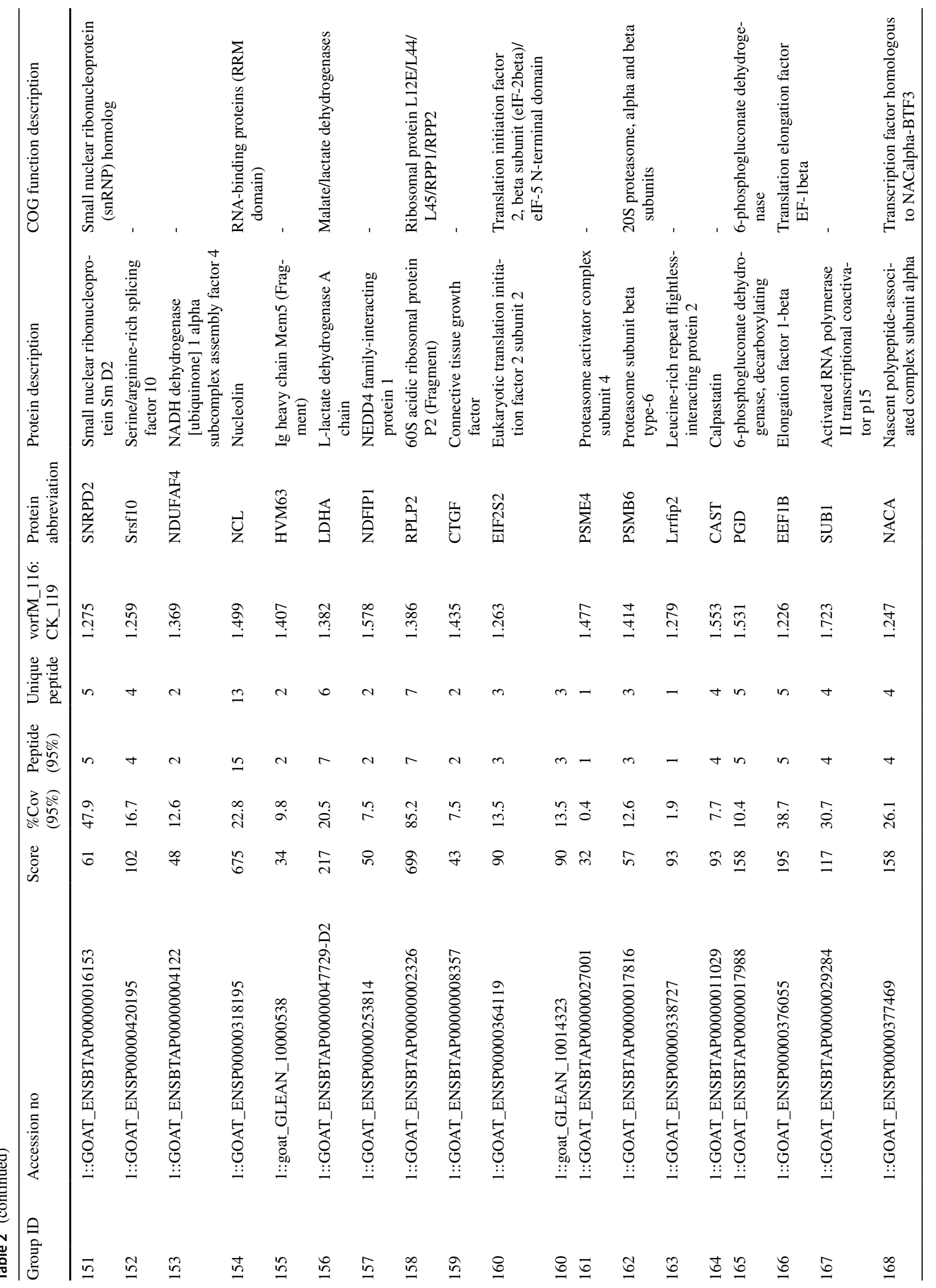




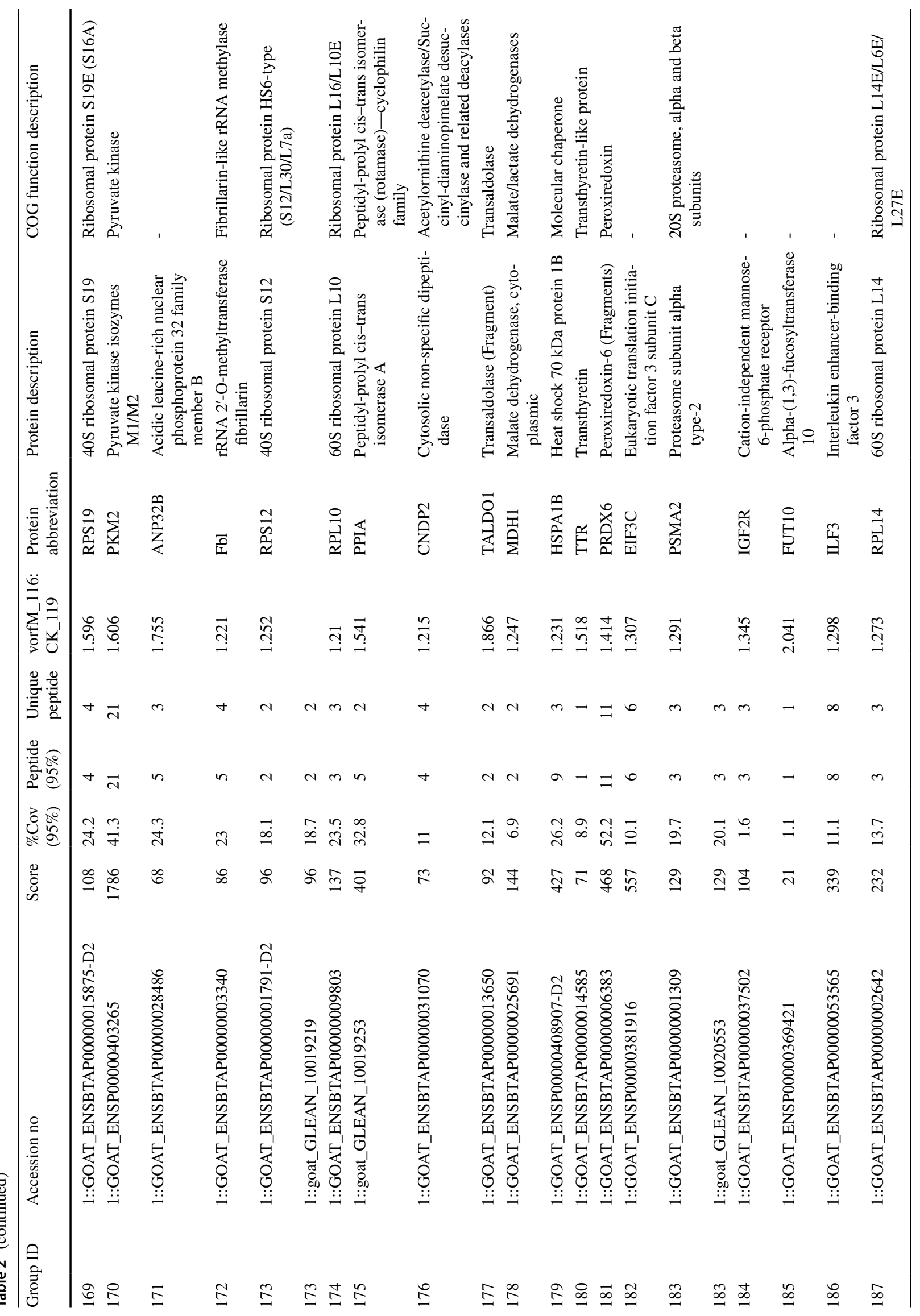




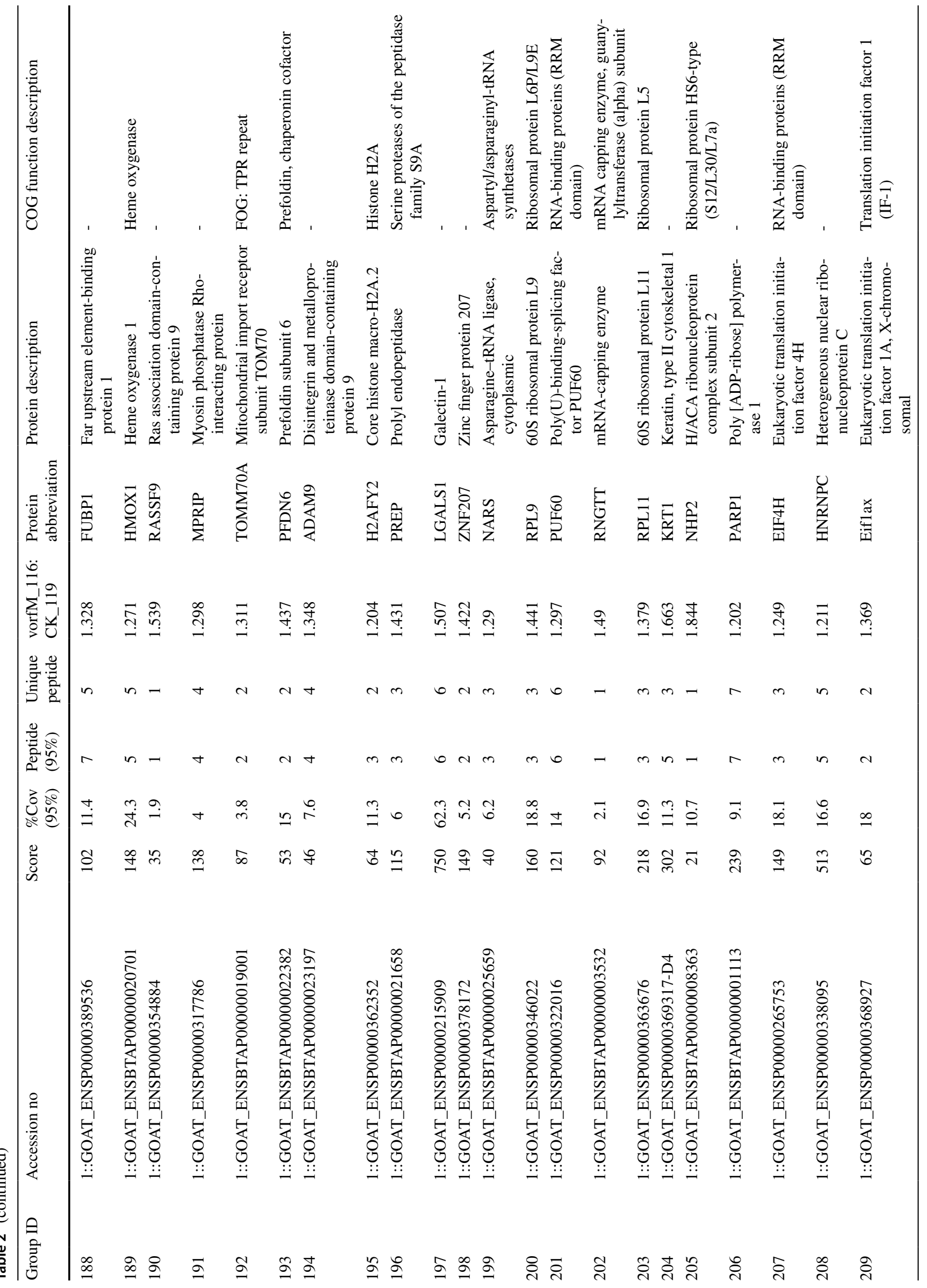




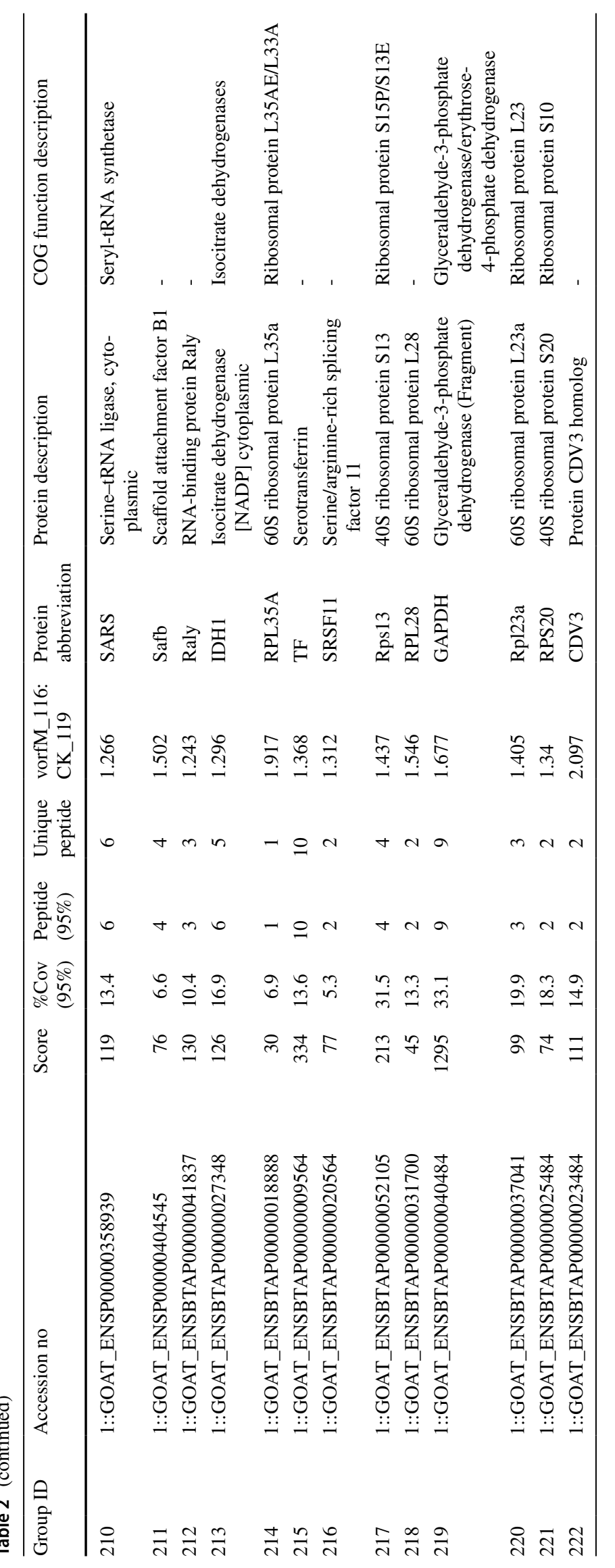




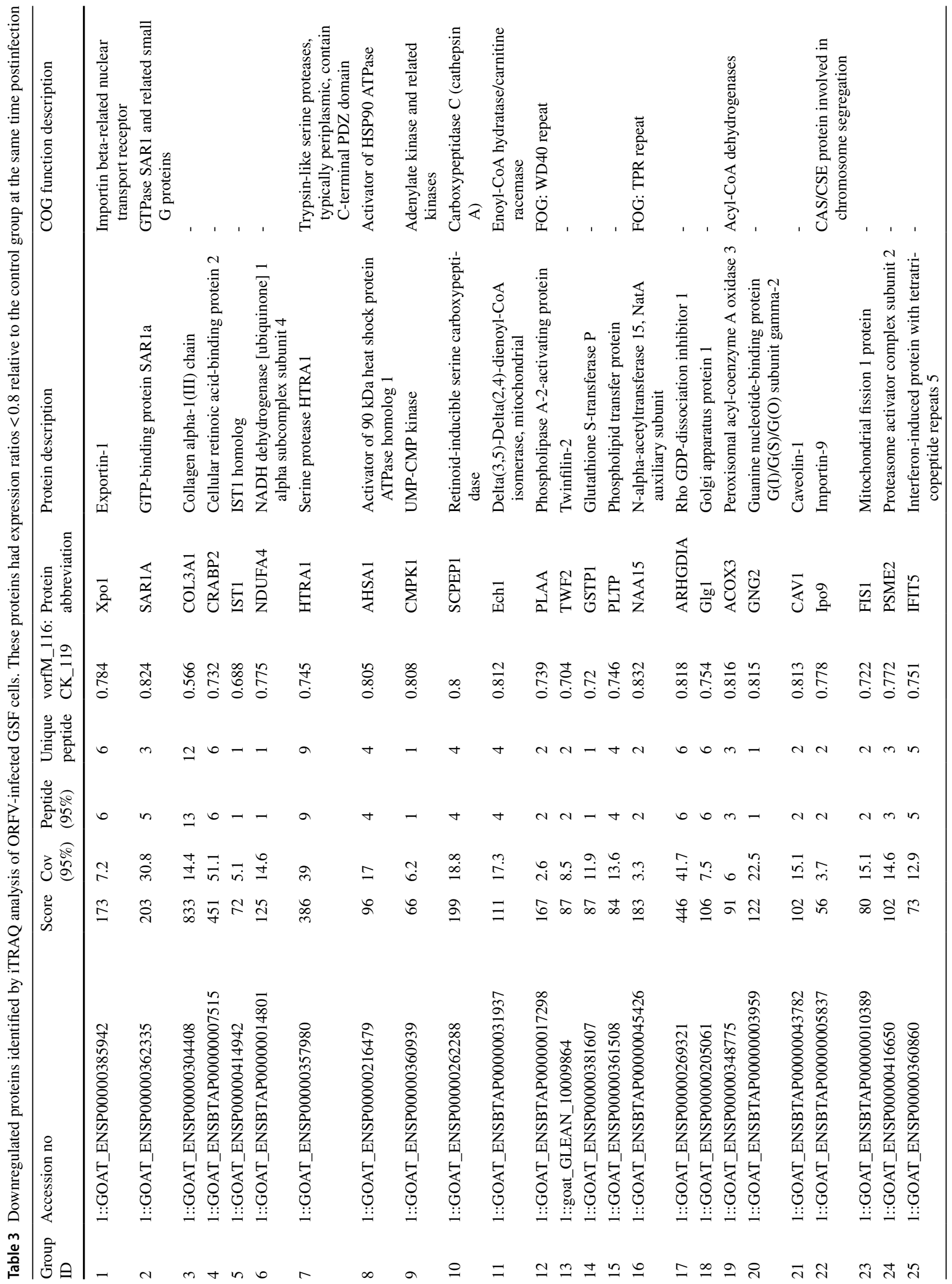




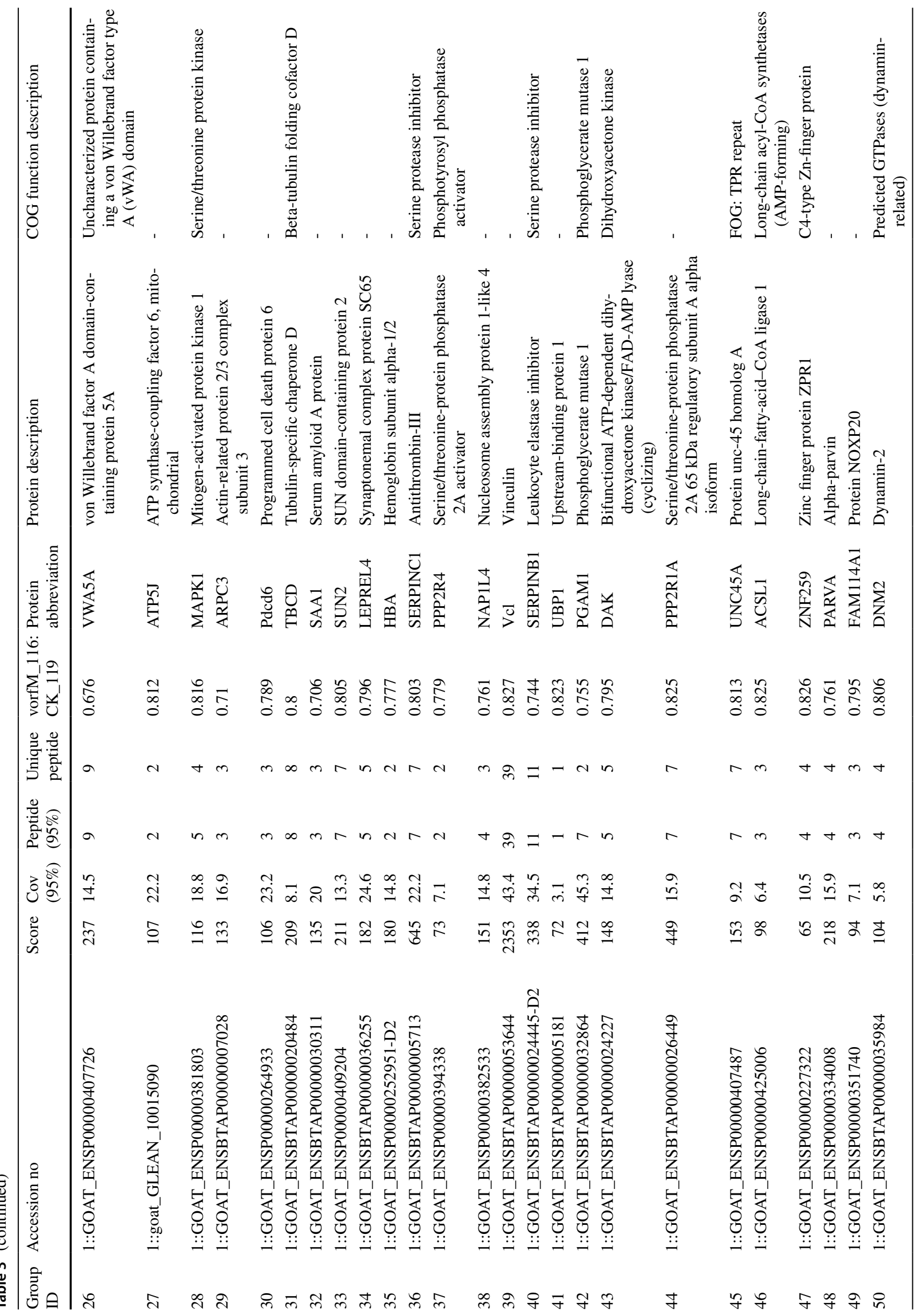




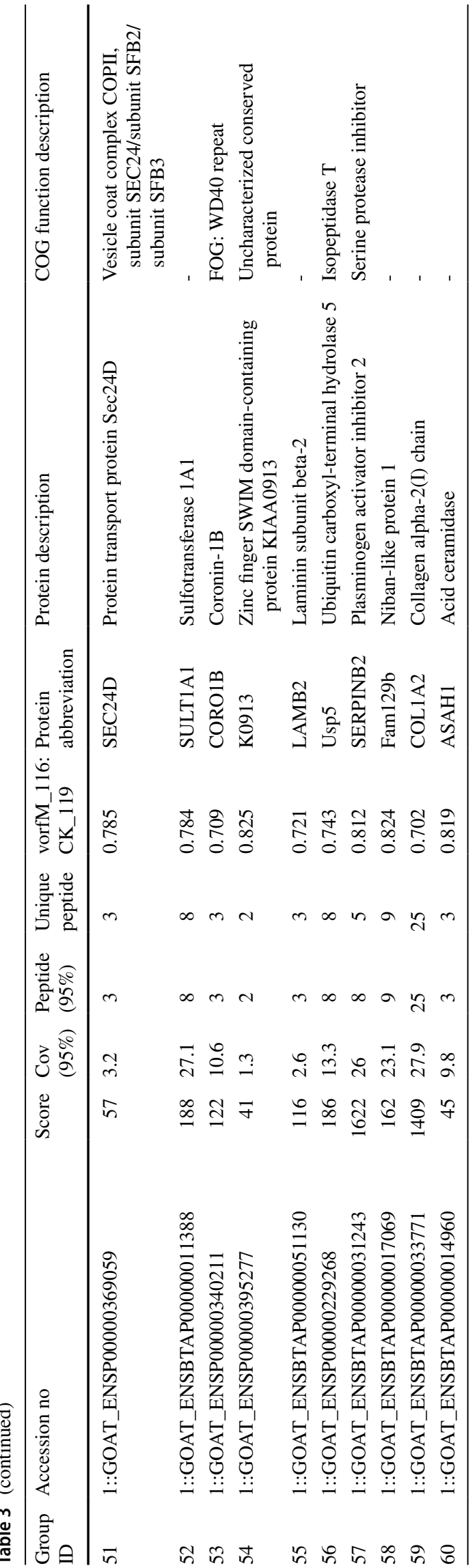

Fig. 3 Classification of the identified proteins based on their functional annotations using Gene Ontology enrichment analysis. (A) Cellular components of the identified proteins. (B) Molecular functions of the identified proteins. (C) Biological processes of the identified proteins. (D) Gene Ontology enrichment analysis of cellular components of differentially expressed proteins. (E) Gene Ontology enrichment analysis of molecular functions of differentially expressed proteins. (F) Gene Ontology enrichment analysis of biological processes of differentially expressed proteins. (G) COG classification of differentially expressed proteins. $P$-values were calculated using MetaCore in the GeneGO package (https://www.genego.com/)

information complementary to the protein expression data obtained by proteomics analysis.

\section{The subcellular localization of HSPA1B}

GSF cells were transfected with the recombinant plasmid pEGFP-HSPA1B for transient expression. The pEGFPHSPA1B protein was used to observe the subcellular localization of HSPA1B using CLSM (Fig. 5A). Following DAPI staining, the nuclear excitation of the blue fluorescence was monitored (Fig. 5B) while the subcellular localization of pEGFP-N1 was monitored (Fig. 5D and E). Compared with pEGFP-N1 (Fig. 5F), the overlap of fluorescence in Fig. 5A and $\mathrm{B}$ indicated that the HSPA1B protein was mainly distributed in the cytoplasm of GSF cells (Fig. 5C).

\section{Inhibition of ORFV proliferation by HSPA1B}

GSF cells were transfected with pEGFP-HSPA1B, cultured for $18 \mathrm{~h}$, and infected with ORFV. Cell suspension samples were collected at different time points after infection to measure virus proliferation by RT-qPCR. The results indicated that the difference in viral proliferation at 6 and $15 \mathrm{~h}$ postinfection between HSPA1B overexpressing cells and the control cells was not statistically significant. However, at 24 and $36 \mathrm{~h}$ postinfection, the viral genome copy number was considerably lower in cells overexpressing HSPA1B, indicating that this protein inhibits proliferation of ORFV in GSF cells (Fig. 6A). Next, we examined ORFV replication in HSPA1B-downregulated cells. HSPA1B was knocked down in GSF cells using RNAi. Three HSPA1B small interfering RNAs (siRNAs) were designed and synthesized, and their silencing efficiency was evaluated using a Western blot assay. SiRNA-517 was found to be the most efficient for decreasing HSPA1B expression (Fig. 6B). GSF cells were transfected with negative- control (NC) siRNA or siRNA-517 and then infected with equal amounts of ORFV. The siRNA knockdown efficiency was confirmed by Western blotting, and the levels of viral RNA and viral proteins in the siRNA-517 cells were compared to NC siRNA cells at different time points after virus infection. The levels of ORFV replication were higher in HSPA1B siRNA cells than 

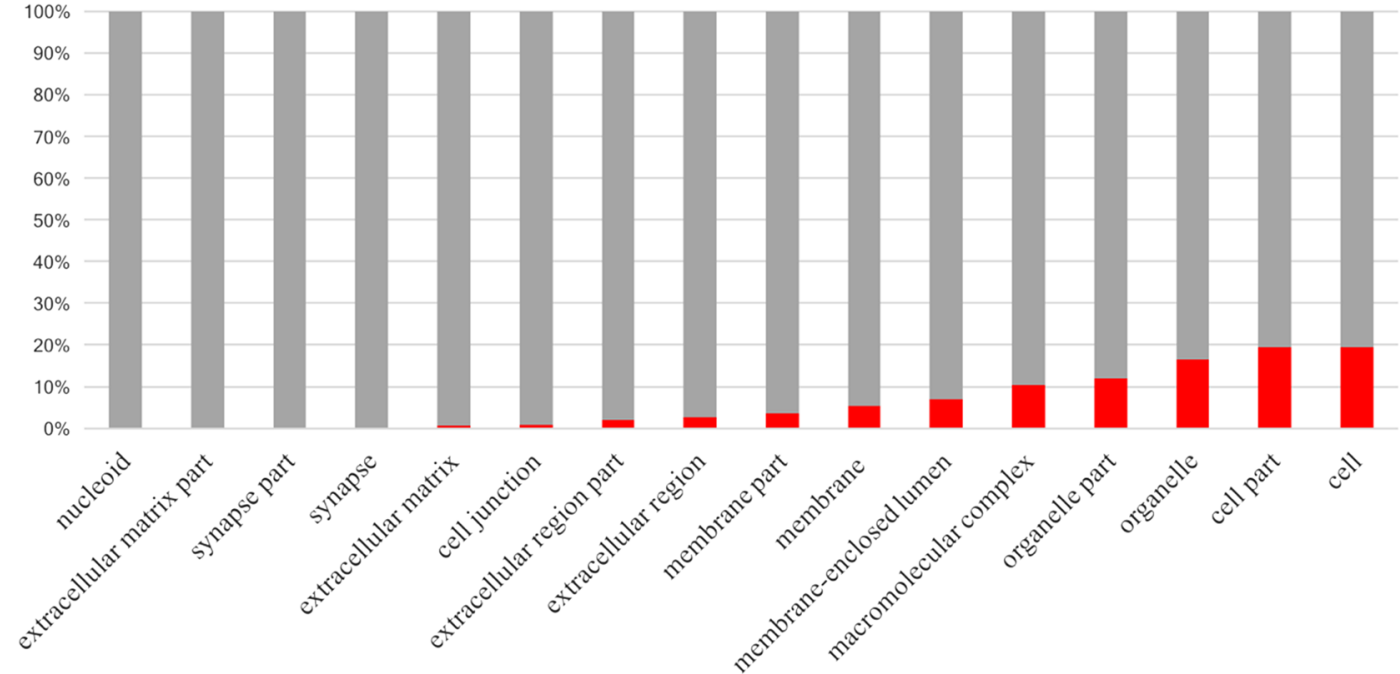

B
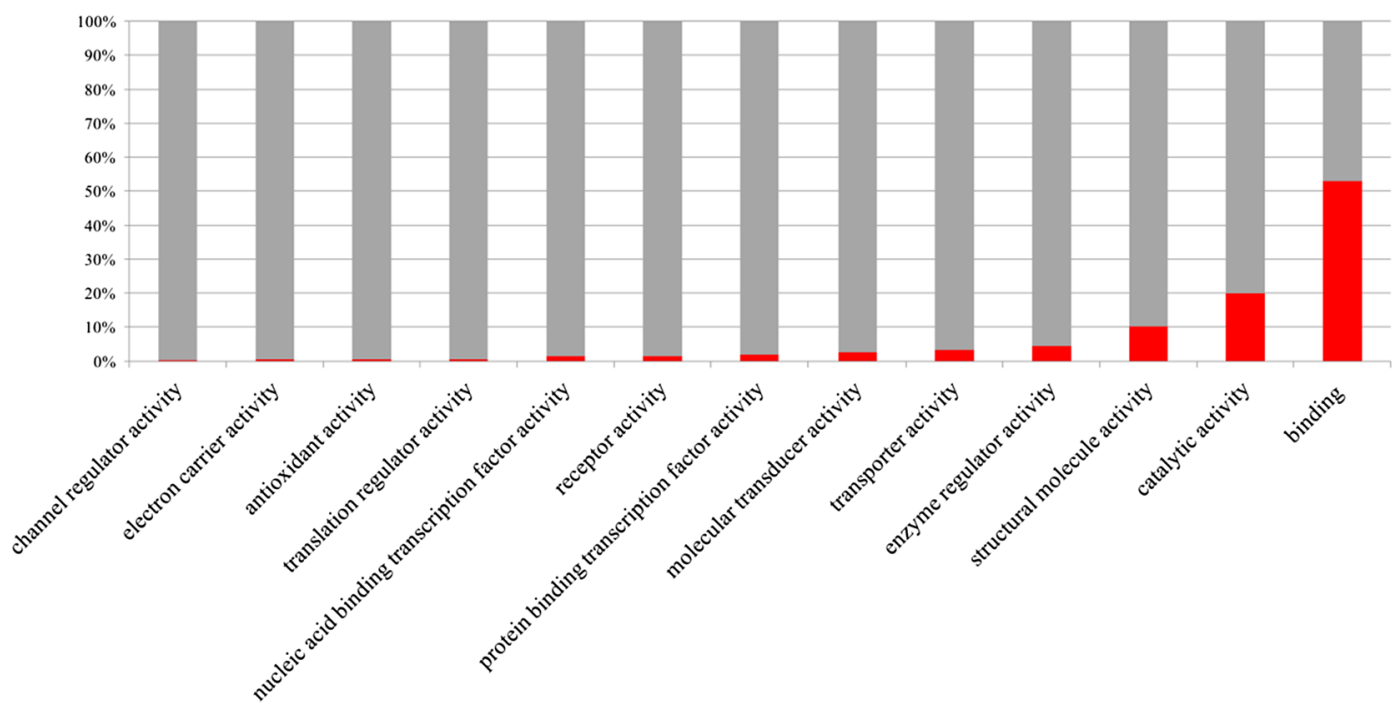

C
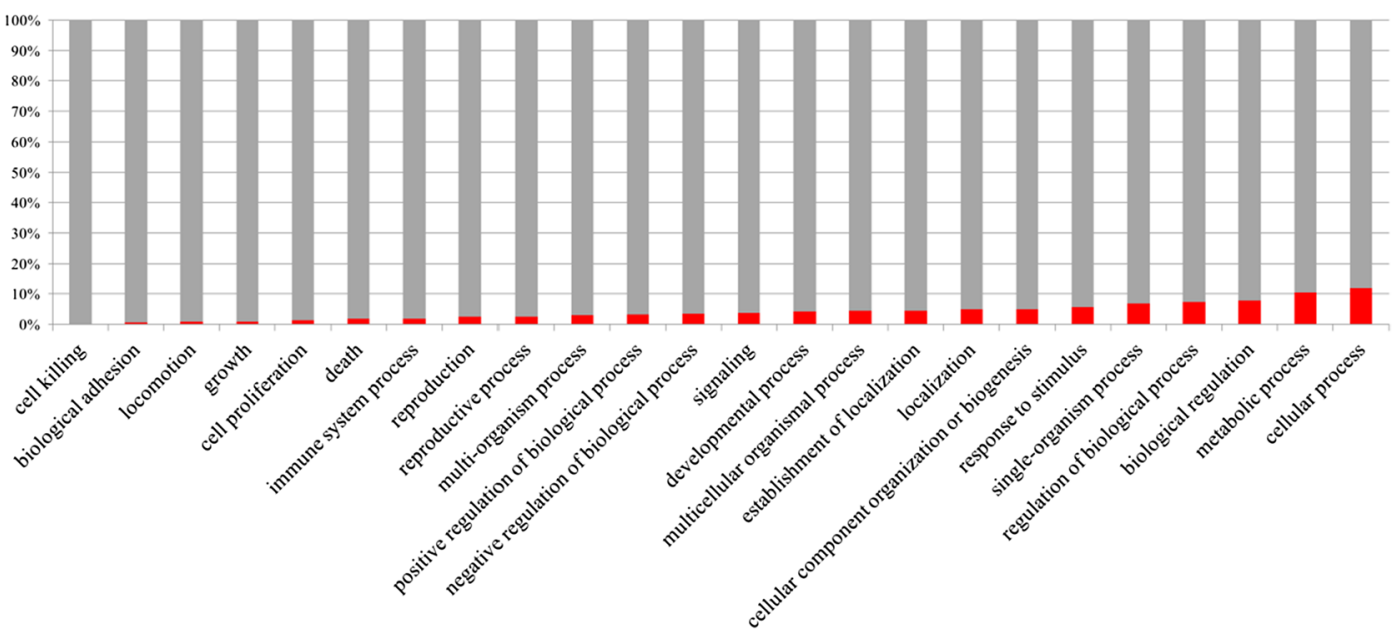


\section{D \\ lar non-membrane-bounded organelle non-membrane-bounded organelle nuclear lumen macromolecular complex proteasome core complex, alpha-subunit complex proteasome core complex nucleus cytosol \\ small ribosomal subunit large ribosomal subunit cytosolic large ribosomal subunit cytosolic small ribosomal subunit ribosome ribonucleoprotein complex ribosomal subunit cytosolic part cytosolic ribosome}

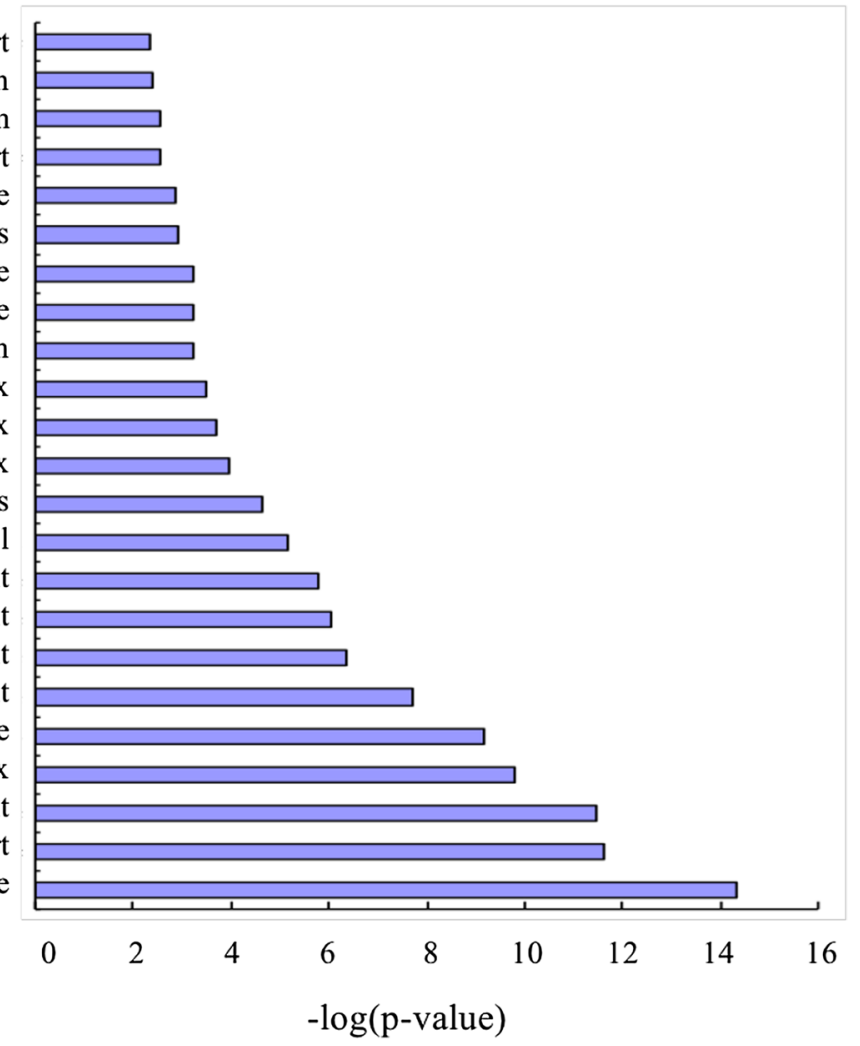

$\mathbf{E}$ carbohydrate derivative binding monosaccharide binding single-stranded DNA binding serine-type exopeptidase activity RS domain binding transferase activity, transferring aldehyde or ketonic groups carbohydrate binding heparin binding heterocyclic compound binding organic cyclic compound binding ribosomal large subunit binding DNA binding growth factor binding mRNA binding

insulin-like growth factor binding rRNA binding threonine-type peptidase activity threonine-type endopeptidase activity structural molecule activity structural constituent of ribosome nucleic acid binding RNA binding

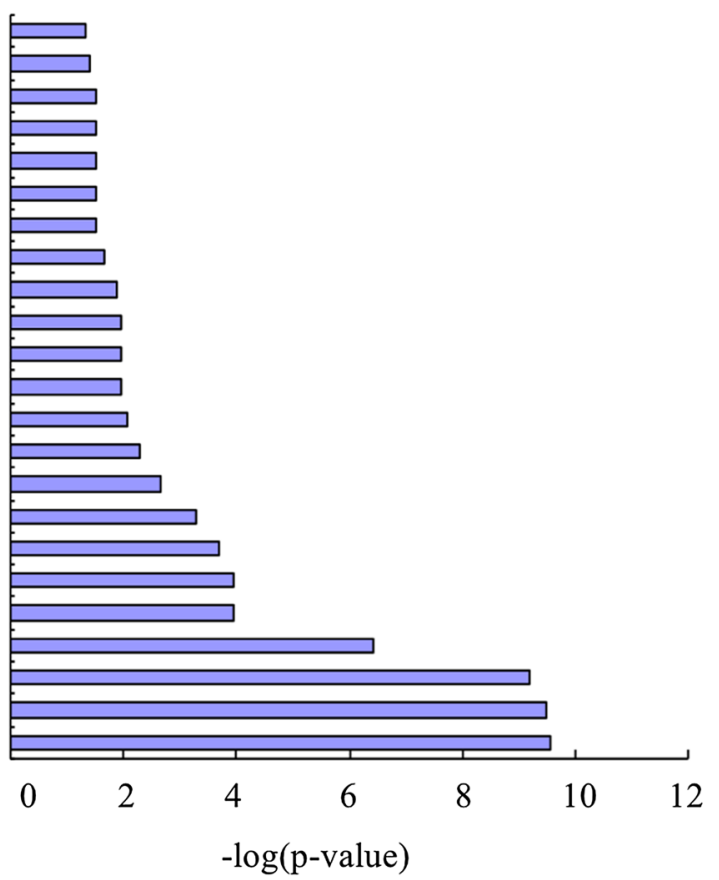

(p-value)

Fig. 3 (continued)

in control cells (Fig. 6C-E), suggesting that ORFV replication was significantly enhanced in the HSPA1B knockdown cells. These data suggest that HSPA1B has an inhibitory effect on ORFV replication in GSF cells. 
F

G

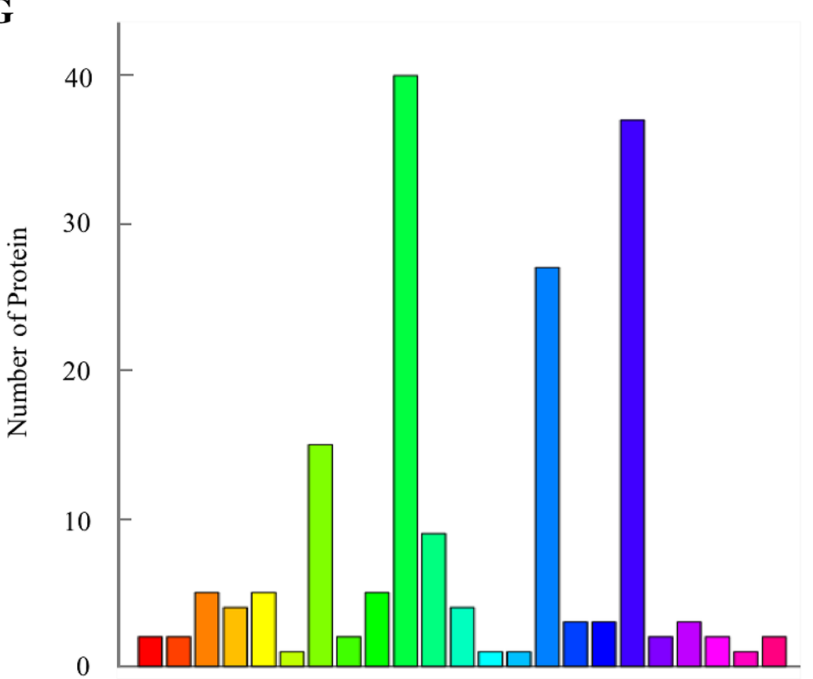

A B C D E F G H I J K L MN O P Q R S T U Y Z

Function Class

RNA biosynthetic process viral reproductive process

RNA metabolic process protein location to endoplasmic reticulum

RNA catabolic process mRNA metabolic process nuclear-transcribed mRNA catabolic process cotranslational protein targeting to membrane mRNA catabolic process establishment of protein localization to endoplasmic reticulum protein targeting to ER SRP-dependent cotranslational protein targeting to membrane Cellular macromolecular complex disassembly Macromolecular complex disassembly translational elongation viral infections cycle cellular protein complex disassembly protein complex disassembly translational initiation viral transcription viral genome expression translational termination nuclear-transcribed mRNA catabolic process, nonsense-mediated decay

\section{。}

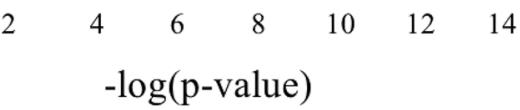

A: RNA processing and modification

B: Chromatin structure and dynamics

C: Energy production and conversion

D: Cell cycle control, cell division, chromosome partitioning

E: Amino acid transport and metabolism

F: Nucleotide transport and metabolism

G: Carbohydrate transport and metabolism

H: Coenzyme transport and metabolism

I: Lipid transport and metabolism

$\mathrm{J}$ : Translation, ribosomal structure and biogenesis

K: Transcription

L: Replication, recombination and repair

M: Cell wail/membrane/envelope biogenesis

$\mathrm{N}$ : Cell motility

O: Posttranslational modification, protein turnover, chaperones

$P$ : Inorganic ion transport and metabolism

Q: Secondary metabolites biosynthesis, transport and catabolism

R: General function prediction only

S: Function unknown

T: Signal transduction, mechanisms

U: Intracellular trafficking, secretion, and vesicular transport

Y: Nuclear structure

$\mathrm{Z}$ : Cytoskeleton

Fig. 3 (continued)

keratinocytes [27]. In a previous study, healthy OFTu cells were inoculated with a filtered viral suspension, and CPE was observed after 7-9 days. After five blind passages of ORFV, approximately $80 \%$ of the cells exhibited rounding, detachment, and clustering, creating a net-like form [9]. In the present study, the proliferation of GSF cells infected with ORFV was studied for the first time, using virus titration, microscopic observations, and RT-qPCR. The data indicated that GSF cells are susceptible to ORFV infection. The proliferation rate was initially slow but increased from 12 to $72 \mathrm{~h}$ postinfection. A one-step growth curve of ORFV in GSF cells showed that the intracellular viral level was the highest at $36 \mathrm{~h}$ postinfection. By $60 \mathrm{~h}$, the cells had detached from the cell plate and the viral titer decreased, possibly due to the lysis of the infected cells. Since GSF cells are derived from the primary host of ORF, they provide a good model system for understanding the changes that occur in these cells following infection with ORFV. In the present 


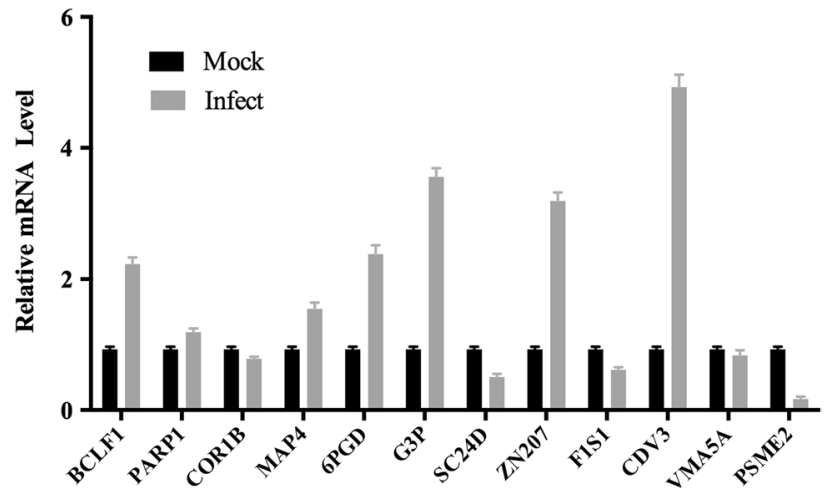

Fig. 4 Confirmation of differential expression by RT-qPCR. RTqPCR was used to verify the differences in the transcription levels of differentially expressed proteins. The results indicated that the abundance of BCLF1, MAP4, 6PGD, G3P, ZN207, and CDV3 mRNA increased, whereas the expression levels of SC24D, FIS1, COR1B, and PSME2 decreased. The expression level of the PARP1 gene was upregulated, although the results were not conclusive. The mRNA level of VMA5A was upregulated following viral infection, but RTqPCR and LC-MS/MS assays showed a decrease in the level of the corresponding protein. This inconsistency could be due to posttranslational modification, including methylation, phosphorylation, or acetylation, or protein for unknown reasons

study, iTRAQ LC - MS/MS was applied for the first time to identify differentially expressed proteins in ORFV-infected GSF cells. The data demonstrated that 282 proteins were differentially expressed, 222 of which were upregulated and 60 of which were downregulated. Changes in mRNA levels measured by RT-qPCR were in agreement with the changes observed for the corresponding proteins by iTRAQ. These findings may be helpful for elucidating the molecular mechanisms by which target cells interact with the virus.

The host cytoskeletal network participates in the transport of viral components, particularly during the stages of entry and exit of the virus [30]. Viral components either hijack the cytoplasmic membrane traffic or interact directly with the cytoskeletal transport machinery [8]. In the present study, the expression levels of two specific proteins involved in cytoskeleton networks and cell communication were altered following ORFV infection. TBCD expression was downregulated, and SPECC1L expression was upregulated.

CD9 promotes adeno-associated virus type 2 infection of mammary carcinoma cells with low cell surface expression of heparan sulfate proteoglycans [19]. Parseval et al. [6] showed that the monoclonal antibody MAb vpg15, which targets a determinant of the feline cell surface marker CD9, which may serve as a receptor or co-receptor for feline immunodeficiency virus (FIV), markedly delayed infection with that virus. In the present study, CD9 was found to be upregulated in infected cells.

We also observed differential expression of components of several ubiquitin-mediated protein degradation pathways in ORFV-infected GSF cells. UBP5 is able to hydrolyze conjugates of the ubiquitin-like protein ISG15, as demonstrated in previous experiments in which these conjugates were shown to bind to the suicide probe ISG15-VS, which in turn inhibited protein degradation [36]. In the present study, UBP5 expression was downregulated, and PSMA7 expression was upregulated in ORFV-infected GSF cells. PSMA7 is a component of the $26 \mathrm{~S}$ proteasome, participating in protein degradation and cell apoptosis. However, PMSA6 and PSME3, which belong to the same protein family, exhibited downregulated expression in infectious bursal disease virus (IBDV)-infected chicken embryo fibroblast (CEF) cells, suggesting that different viruses may use different pathways to regulate protein degradation and cell apoptosis [43].

It is noteworthy that ATP synthase-coupling factor 6 (ATP5J), which is involved in ATP synthesis-coupled proton transport [37], exhibited decreased expression in ORFVinfected cells. A total of six proteins with receptor activity were identified in ORFV-infected GSF cells. TR150, K2C1,
Fig. 5 The subcellular localization of HSPA1B. A monolayer of GSF cells was transfected by conventional methods using empty pEGFP-N1 as a control. Expression of the fusion protein in GSF cells was detected 18-24 h after transfection by confocal laser scanning microscopy. A. Green fluorescence showing the location of pEGFP-HSPA1B. B. Nuclear staining of pEGFP-HSPA1B. C. Merged image of panels $A$ and B. D. Green fluorescence showing the location of pEGFP-N1. E. Nuclear staining of pEGFPN1. F. Merged image of panels $\mathrm{D}$ and $\mathrm{E}$

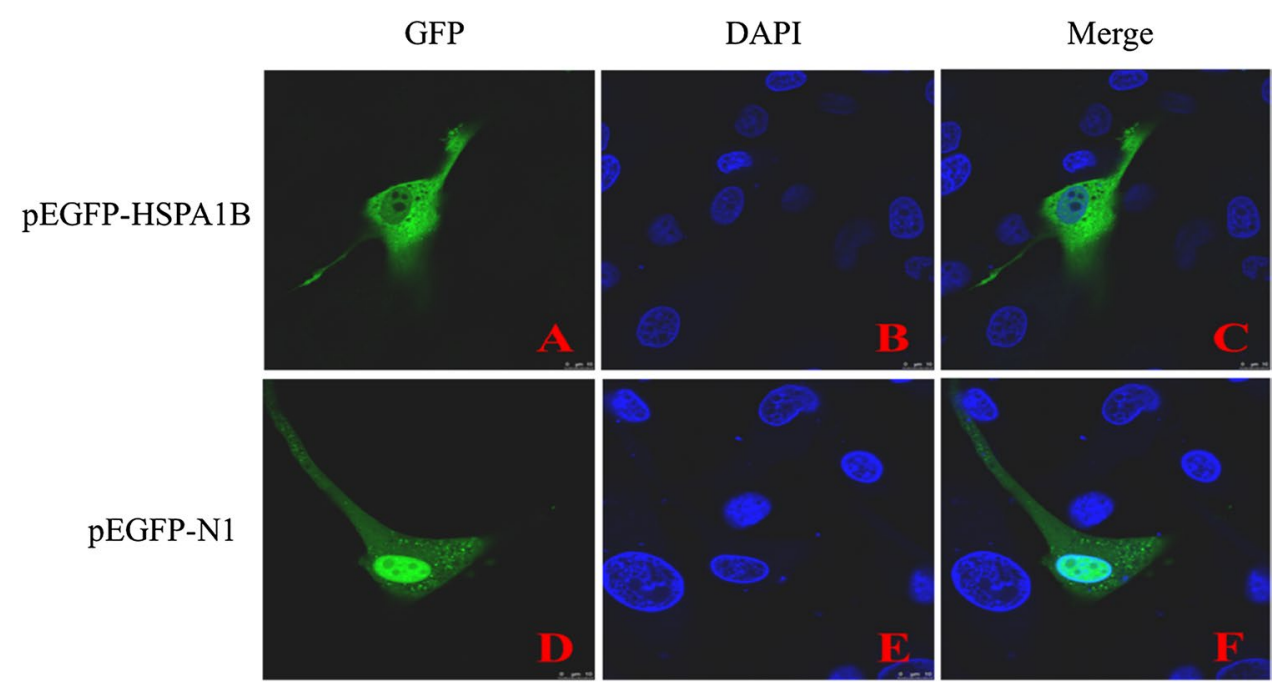




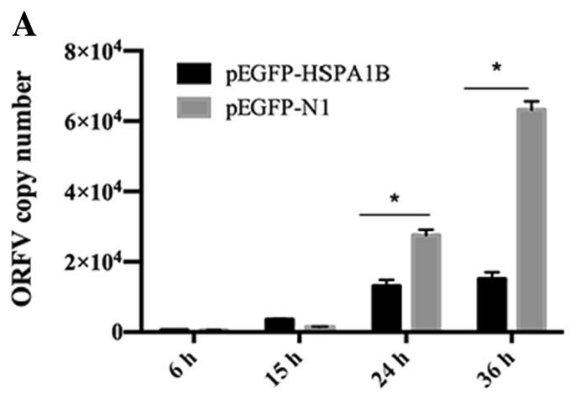

C

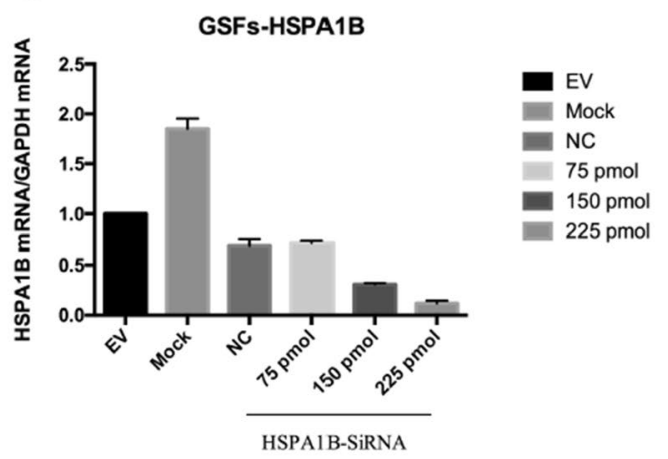

B

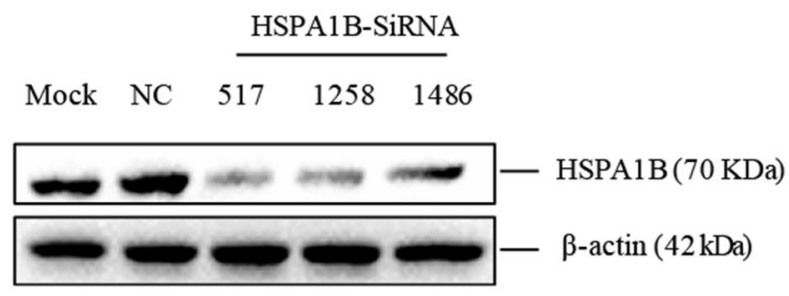

D

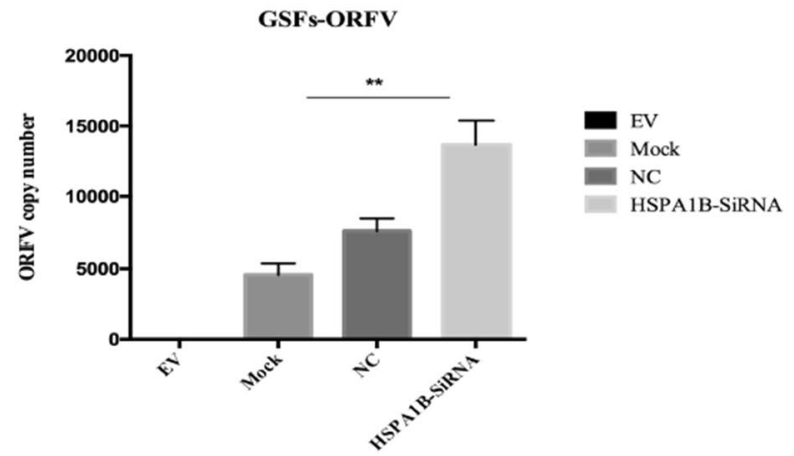

$\mathbf{E}$

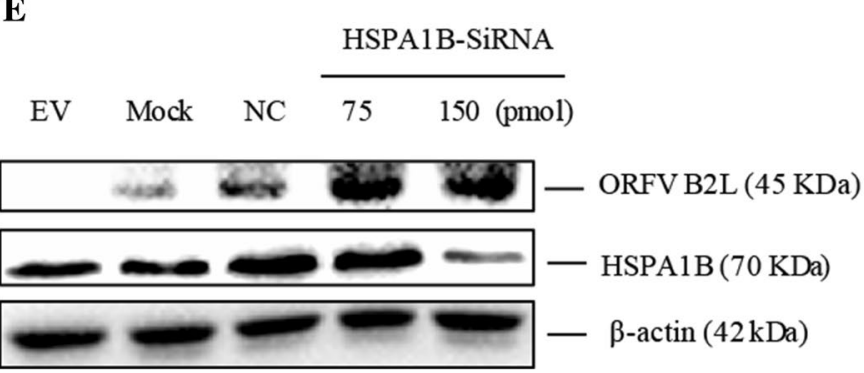

Fig. 6 HSPA1B inhibits ORFV replication. (A) Overexpression of HSPA1B suppresses ORFV replication. GSF cells were transfected with pEGFP-HSPA1B and pEGFP-N1 and infected $18 \mathrm{~h}$ later with ORFV at an MOI of 0.1. Cultured cells were collected at 6, 15, 24, and $36 \mathrm{~h}$ postinfection, and the viral DNA content was measured by RT-qPCR. (B) Evaluation of the efficiency of NC or HSPA1B siRNA in silencing HSPA1B expression. GSF cells were transfected with

SUCR1, MPRI, O10AG, and TKT were upregulated. Transketolase (TK) catalyzes several reactions in the non-oxidative branch of the pentose phosphate pathway (PPP) and serves as a bridge between the oxidative part of the PPP and the oxidative decarboxylation of glucose [17]. Recently, it has been reported that TK and its cofactor thiamine have a very high growth control coefficient. TR150 has been shown to be involved in pre-mRNA splicing and was previously believed to participate in transcriptional co-activation via its association with the TRAP complex. However, studies have not shown TR150 to be a subunit of a stable mediator
$150 \mathrm{nM}$ HSPA1B siRNA or NC, and the expression of HSPA1B mRNA or protein was detected by Western blotting. (C-E) Downregulation of HSPA1B promotes ORFV replication. GSF cells were transfected with NC siRNA or HSPA1B siRNA and subsequently infected with equal amounts of ORFV at an MOI of 0.1. The expression of HSPA1B and viral mRNA or protein was detected by RTqPCR or Western blotting

complex $[16,20]$. $\mathrm{K} 2 \mathrm{C} 1$ may regulate the activity of kinases, such as PKC and SRC via binding to integrin beta-1 (ITB1) and the receptor of activated protein kinase C (RACK1/ GNB2L1). Additionally, it can form a complex with C1QBP, which is a high-affinity receptor for kininogen-1/HMWK. The functions of these proteins in infected host cells are not well understood.

HSPA1B is a member of the HSP70 family. The expression level of HSP70 rapidly increases in response to cellular stresses (e.g., heat shock) or in response to certain viral infections $[4,21,24,26]$. Genetic variations in HSP70 have 
been found to be associated with individual susceptibility to several diseases by alterations in protein expression and/or function. Studies have shown that HSPs may play a significant role in virus-host cell interactions during viral infection in vivo and in vitro $[1,31]$. HSP70 stabilizes proteins against aggregation and mediates the folding of newly translated polypeptides in the cytosol, as well as within organelles. It can bind with nucleotides via an ATP-dependent process and is involved in the response to stress as well as in cell apoptosis. HSP70 is associated with membrane microdomains (lipid rafts) in response to dengue virus infection and acts as a receptor complex in human cell lines and in monocytes/ macrophages that are susceptible to dengue virus (DENV) infection [32]. Therefore, we hypothesize that the increased expression level of HSP70 protein may play a substantial role in the replication of ORFV. In the present study, the recombinant plasmid construct pEGFP-HSPA1B transiently expressed in GSF cells and was found to be localized in the cytoplasm. Interestingly, it has been reported that HSP70 and HSP90 are clustered around CD14, preventing them from interacting with DENV, when monocytes are incubated with "lipopolysaccharide" prior to DENV infection [32]. Our results offer an explanation for this finding. To study the effects of ORFV on cell proliferation and HSPA1B expression, GSF cells overexpressing the HSPA1B protein were infected with ORFV and viral proliferation was assessed. The results suggested that HSPA1B inhibits proliferation of ORFV in GSF cells, and this appears to occur in the middle of the viral replication cycle. Furthermore, ORFV replication was significantly enhanced in HSPA1B knockdown cells, again suggesting that HSPA1B plays an important role in ORFV-infected GSF cells. Importantly, animals are not protected against ORFV reinfections, which may be in part due to short-lived ORFV-specific adaptive immunity. Poxviruses encode a considerable number of gene products that allow them to evade the host immune response [35]. These evasive strategies may play a major role in supporting ORFV replication and allowing ORFV reinfections to occur.

Acknowledgements This study was supported by the National Key R\&D Program of China (2018YFD0502100). The authors would like to thank the anonymous editors and reviewers for their valuable comments and suggestions, which helped to improve the quality of this manuscript.

\section{References}

1. Braga ACS, Carneiro BM, Batista MN, Akinaga MM, Bittar C, Rahal P (2017) Heat shock proteins HSPB8 and DNAJC5B have HCV antiviral activity. PLoS ONE 12:e0188467

2. Carbon S, Ireland A, Mungall CJ, Shu S, Marshall B, Lewis S, Ami GOH, Web Presence Working G (2009) AmiGO: online access to ontology and annotation data. Bioinformatics $25: 288-289$
3. Carvalho RN, Lettieri T (2011) Proteomic analysis of the marine diatom Thalassiosira pseudonana upon exposure to benzo(a)pyrene. BMC Genom 12:159

4. Cheung RK, Dosch HM (1993) The growth transformation of human B cells involves superinduction of hsp70 and hsp90. Virology 193:700-708

5. Chittur S, Parr B, Marcovici G (2011) Inhibition of inflammatory gene expression in keratinocytes using a composition containing carnitine, thioctic Acid and saw palmetto extract. Evid Based Complement Alternat Med 2011:985345

6. de Parseval A, Lerner DL, Borrow P, Willett BJ, Elder JH (1997) Blocking of feline immunodeficiency virus infection by a monoclonal antibody to CD9 is via inhibition of virus release rather than interference with receptor binding. J Virol 71:5742-5749

7. Deane D, McInnes CJ, Percival A, Wood A, Thomson J, Lear A, Gilray J, Fleming S, Mercer A, Haig D (2000) Orf virus encodes a novel secreted protein inhibitor of granulocyte-macrophage colony-stimulating factor and interleukin-2. J Virol 74:1313-1320

8. Dohner K, Sodeik B (2005) The role of the cytoskeleton during viral infection. Curr Top Microbiol Immunol 285:67-108

9. Duan C, Liao M, Wang H, Luo X, Shao J, Xu Y, Li W, Hao W, Luo $S$ (2015) Identification, phylogenetic evolutionary analysis of GDQY orf virus isolated from Qingyuan City, Guangdong Province, southern China. Gene 555:260-268

10. Fleming SB, Haig DM, Nettleton P, Reid HW, McCaughan CA, Wise LM, Mercer A (2000) Sequence and functional analysis of a homolog of interleukin-10 encoded by the parapoxvirus orf virus. Virus Genes 21:85-95

11. Haig DM, Fleming S (1999) Immunomodulation by virulence proteins of the parapoxvirus orf virus. Vet Immunol Immunopathol $72: 81-86$

12. Haig DM (2001) Subversion and piracy: DNA viruses and immune evasion. Res Vet Sci 70:205-219

13. Haig DM, McInnes CJ (2002) Immunity and counter-immunity during infection with the parapoxvirus orf virus. Virus Res $88: 3-16$

14. Han B, Chen S, Dai S, Yang N, Wang T (2010) Isobaric tags for relative and absolute quantification- based comparative proteomics reveals the features of plasma membrane-associated proteomes of pollen grains and pollen tubes from Lilium davidii. J Integr Plant Biol 52:1043-1058

15. Hare NJ, Solis N, Harmer C, Marzook NB, Rose B, Harbour C, Crossett B, Manos J, Cordwell SJ (2012) Proteomic profiling of Pseudomonas aeruginosa AES-1R, PAO1 and PA14 reveals potential virulence determinants associated with a transmissible cystic fibrosis-associated strain. BMC Microbiol 12:16

16. Heyd F, Lynch KW (2010) Phosphorylation-dependent regulation of PSF by GSK3 controls CD45 alternative splicing. Mol Cell 40:126-137

17. Horecker BL (2002) The pentose phosphate pathway. J Biol Chem 277:47965-47971

18. Hosamani M, Scagliarini A, Bhanuprakash V, McInnes CJ, Singh RK (2009) Orf: an update on current research and future perspectives. Expert Rev Anti Infect Ther 7:879-893

19. Kurzeder C, Koppold B, Sauer G, Pabst S, Kreienberg R, Deissler H (2007) CD9 promotes adeno-associated virus type 2 infection of mammary carcinoma cells with low cell surface expression of heparan sulphate proteoglycans. Int J Mol Med 19:325-333

20. Lee KM, Hsu Ia W, Tarn WY (2010) TRAP150 activates premRNA splicing and promotes nuclear mRNA degradation. Nucleic Acids Res 38:3340-3350

21. Lefeuvre A, Contamin H, Decelle T, Fournier C, Lang J, Deubel V, Marianneau P (2006) Host-cell interaction of attenuated and wild-type strains of yellow fever virus can be differentiated at early stages of hepatocyte infection. Microbes Infect 8:1530-1538 
22. Li X, Shang B, Li YN, Shi Y, Shao C (2019) IFNgamma and TNFalpha synergistically induce apoptosis of mesenchymal stem/ stromal cells via the induction of nitric oxide. Stem Cell Res Ther $10: 18$

23. Li Z, Zhang Q, Zhang Q, Xu M, Qu Y, Cai X, Lu L (2016) CXCL6 promotes human hepatocyte proliferation through the CXCR1NFkappaB pathway and inhibits collagen I secretion by hepatic stellate cells. Biochem Cell Biol 94:229-235

24. Liao WJ, Fan PS, Fu M, Fan XL, Liu YF (2005) Increased expression of $70 \mathrm{kD}$ heat shock protein in cultured primary human keratinocytes induced by human papillomavirus 16 E6/E7 gene. Chin Med J (Engl) 118:2058-2062

25. Lyttle DJ, Fraser KM, Fleming SB, Mercer AA, Robinson AJ (1994) Homologs of vascular endothelial growth factor are encoded by the poxvirus orf virus. J Virol 68:84-92

26. Mayer MP (2005) Recruitment of Hsp70 chaperones: a crucial part of viral survival strategies. Rev Physiol Biochem Pharmacol 153:1-46

27. McKeever DJ, Jenkinson DM, Hutchison G, Reid HW (1988) Studies of the pathogenesis of orf virus infection in sheep. J Comp Pathol 99:317-328

28. Mercer AA, Fleming SB, Ueda N (2005) F-box-like domains are present in most poxvirus ankyrin repeat proteins. Virus Genes 31:127-133

29. Naing A, Infante JR, Papadopoulos KP, Chan IH, Shen C, Ratti NP, Rojo B, Autio KA, Wong DJ, Patel MR, Ott PA, Falchook GS, Pant S, Hung A, Pekarek KL, Wu V, Adamow M, McCauley S, Mumm JB, Wong P, Van Vlasselaer P, Leveque J, Tannir NM, Oft M (2018) PEGylated IL-10 (Pegilodecakin) induces systemic immune activation, CD8(+) T cell invigoration and polyclonal $\mathrm{T}$ cell expansion in cancer patients. Cancer Cell 34:775-791.e773

30. Radtke K, Dohner K, Sodeik B (2006) Viral interactions with the cytoskeleton: a hitchhiker's guide to the cell. Cell Microbiol $8: 387-400$

31. Rathore AP, Haystead T, Das PK, Merits A, Ng ML, Vasudevan SG (2014) Chikungunya virus nsP3 \& nsP4 interacts with HSP-90 to promote virus replication: HSP-90 inhibitors reduce CHIKV infection and inflammation in vivo. Antiviral Res 103:7-16

32. Reyes-Del Valle J, Chavez-Salinas S, Medina F, Del Angel RM (2005) Heat shock protein 90 and heat shock protein 70 are components of dengue virus receptor complex in human cells. J Virol 79:4557-4567

33. Ross PL, Huang YN, Marchese JN, Williamson B, Parker K, Hat$\tan$ S, Khainovski N, Pillai S, Dey S, Daniels S, Purkayastha S, Juhasz P, Martin S, Bartlet-Jones M, He F, Jacobson A, Pappin DJ (2004) Multiplexed protein quantitation in Saccharomyces cerevisiae using amine-reactive isobaric tagging reagents. Mol Cell Proteomics 3:1154-1169
34. Savory LJ, Stacker SA, Fleming SB, Niven BE, Mercer AA (2000) Viral vascular endothelial growth factor plays a critical role in orf virus infection. J Virol 74:10699-10706

35. Seet BT, Johnston J, Brunetti CR, Barrett JW, Everett H, Cameron C, Sypula J, Nazarian SH, Lucas A, McFadden G (2003) Poxviruses and immune evasion. Annu Rev Immunol 21:377-423

36. Sijts A, Sun Y, Janek K, Kral S, Paschen A, Schadendorf D, Kloetzel PM (2002) The role of the proteasome activator PA28 in MHC class I antigen processing. Mol Immunol 39:165-169

37. Tezara W, Mitchell V, Driscoll S, Lawlor D (1999) Water stress inhibits plant photosynthesis by decreasing coupling factor and ATP. Nature 401:914-917

38. Wang R, Wang Y, Liu F, Luo S (2019) Orf virus: A promising new therapeutic agent. Rev Med Virol 29:e2013

39. Wilf NM, Reid AJ, Ramsay JP, Williamson NR, Croucher NJ, Gatto L, Hester SS, Goulding D, Barquist L, Lilley KS, Kingsley RA, Dougan G, Salmond GP (2013) RNA-seq reveals the RNA binding proteins, Hfq and RsmA, play various roles in virulence, antibiotic production and genomic flux in Serratia sp. ATCC 39006. BMC Genom 14:822

40. Wise LM, Veikkola T, Mercer AA, Savory LJ, Fleming SB, Caesar C, Vitali A, Makinen T, Alitalo K, Stacker SA (1999) Vascular endothelial growth factor (VEGF)-like protein from orf virus NZ2 binds to VEGFR2 and neuropilin-1. Proc Natl Acad Sci USA 96:3071-3076

41. Wisniewski JR, Zougman A, Mann M (2009) Combination of FASP and StageTip-based fractionation allows in-depth analysis of the hippocampal membrane proteome. J Proteome Res 8:5674-5678

42. Zhu Z, Wang G, Yang F, Cao W, Mao R, Du X, Zhang X, Li C, Li D, Zhang K, Shu H, Liu X, Zheng H (2016) Foot-andMouth Disease Virus Viroporin 2B Antagonizes RIG-I-mediated antiviral effects by inhibition of its protein expression. J Virol 90:11106-11121

43. Zou W, Ke J, Zhang A, Zhou M, Liao Y, Zhu J, Zhou H, Tu J, Chen H, Jin M (2010) Proteomics analysis of differential expression of chicken brain tissue proteins in response to the neurovirulent $\mathrm{H} 5 \mathrm{~N} 1$ avian influenza virus infection. J Proteome Res 9:3789-3798

Publisher's Note Springer Nature remains neutral with regard to jurisdictional claims in published maps and institutional affiliations. 